\title{
Study of the Importance of Non-Uniform Mass Density in Numerical Simulations of Fire Spread over MDF Panels in a Corner Configuration
}

\author{
Davood Zeinali ${ }^{a, *}$, Ankur Gupta ${ }^{b}$, Georgios Maragkos ${ }^{a}$, Gaurav Agarwal ${ }^{b}$, \\ Tarek Beji ${ }^{a}$, Marcos Chaos ${ }^{b, * *}$, Yi Wang ${ }^{b}$, Joris Degroote ${ }^{a}$ and Bart Merci ${ }^{a}$ \\ ${ }^{a}$ Department of Flow, Heat and Combustion Mechanics, Ghent University, EA03, \\ Sint-Pietersnieuwstraat 41, 9000 Gent, Belgium \\ ${ }^{b}$ Research Division, FM Global, 1151 Boston-Providence Turnpike, Norwood, MA \\ 02062, USA \\ *Corresponding author: davood.zeinali@ugent.be \\ ** Current affiliation: Materials Science Division, Energetic Materials Center, Lawrence \\ Livermore National Laboratory, 7000 East Avenue, P.O. Box 808, M/S L-288, \\ Livermore, CA 94550-9234, USA
}

\section{Abstract}

The distribution of mass density through the thickness of Medium Density Fiberboard (MDF) panels is known to be non-uniform. A few studies have previously investigated the influence of this non-uniform through-thickness density distribution on the thermal behavior of MDF panels in small-scale tests. This study assesses the significance of this material property on flame spread simulations in a medium-scale set-up, namely that of Single Burning Item (SBI) corner fire tests. Simulations are performed using FireFOAM 2.2.x, considering both uniform and non-uniform MDF material density profiles, using model-effective material properties determined from bench-scale pyrolysis tests conducted in a Fire Propagation Apparatus (FPA). The heat transfer from the gas phase is modeled by means of empirical expressions with adjusted parameters. The simulations are assessed against the results of several SBI experiments with MDF panels and a test with Calcium Sil- 
icate (CS) panels. When the non-uniform nature of the through-thickness density is taken into account, the fire growth prediction in terms of the total Heat Release Rate (HRR) is considerably different ( $20 \%$ higher peak HRR), mainly due to the characteristic high peak mass loss rate at the initiation of pyrolysis of MDF material, resulting from the higher mass density near the surface of the panels. Furthermore, total heat fluxes on the panels, lateral flame spread, surface pyrolysis and through-thickness char formation visibly depend on the non-uniform distribution of mass density, particularly in regions further away from the corner where the influence of thermal attack from the burner is less dominant. A new diagnostic is proposed for determining the pyrolysis front location and spread on the surface of the charring panels.

Keywords: MDF, corner fire, modeling, FireFOAM, density profile, non-uniform

\section{Introduction}

Modeling the burning behavior of engineered wood products such as medium density fiberboard (MDF) panels is of ample interest in the fire safety community today since these modern materials are widely used in furniture, flooring and decoration in our buildings. MDF panels, in particular, exhibit density variation across their thickness as a result of their manufacturing process $[1,2]$. This non-uniform through-thickness density distribution in turn plays a role in the thermal behavior of MDF panels.

Previous studies have investigated this non-uniform density effect in smallscale tests $[3,4,5]$, but here we investigate the significance of this material property on flame spread simulations in a medium scale set-up, namely that 
of Single Burning Item (SBI) tests [6].

The SBI test [6] constitutes a corner fire test, bridging a gap between bench-scale tests such as Fire Propagation Apparatus (FPA) tests [7, 8] and full-scale tests such as ISO Room Corner tests [9]. The SBI test, in addition, forms the basis for classification of linings in Europe [10]. This paper presents a numerical study of the corner fire experiments with Calcium Silicate (CS) and MDF panels that have been described in $[11,12]$.

Large Eddy Simulations (LES) are performed using the fire modeling code FireFOAM 2.2.x [13, 14], developed based on the OpenFOAM platform [15]. At first, a simulation is discussed corresponding to the experiment with CS panels [11]. There is no flame spread on the panels in this case, making it possible to assess the predicted flame height and heat fluxes of the burner itself. Subsequently, the MDF simulations are discussed and evaluated against the experiments with MDF panels [12], including results of total Heat Release Rates (HRR), total heat fluxes and flame heights, considering cases with both uniform and non-uniform mass density profiles through the thickness of the panels. In addition, results of fire spread and pyrolysis front propagation are discussed, using a new diagnostic based on char fraction. Moreover, the influence of non-uniform mass density on through-thickness char formation is examined.

\section{Experimental set-up and tests}

The details of the set-up and testing methodology have been reported in [11], and the tests with MDF panels have been discussed in [12]. A total of 4 tests were conducted at a burner HRR of $30 \mathrm{~kW}$, including 1 test with 


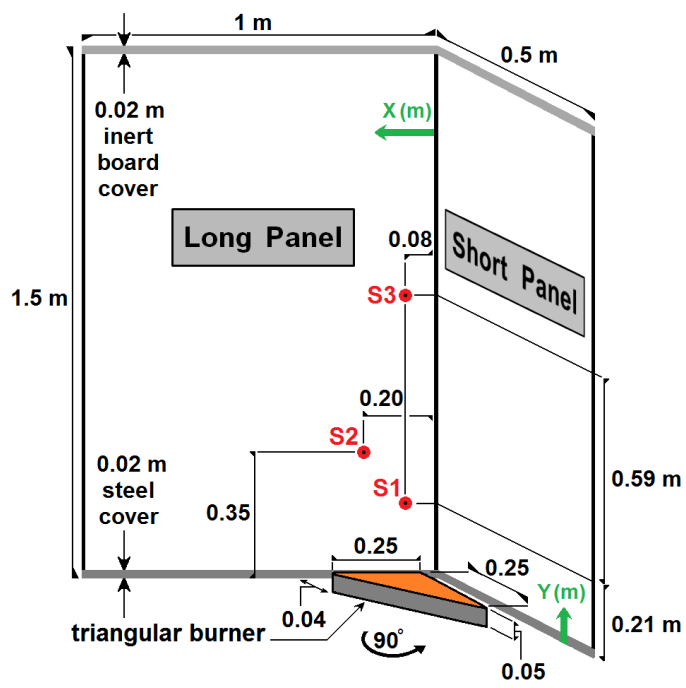

Figure 1: The set-up of the SBI experiments [11, 12] (all distance units in meters), showing the locations of heat flux measurement using Schmidt-Boelter sensors S1 to S3 (The heat flux sensors are set flush with the surface of the panels. $X$ and $Y$ denote the horizontal and vertical axes, respectively, shown with green arrows. (For interpretation of the references to color in this figure legend, the reader is referred to the web version of this article.)

CS panels (' $C S C S$ ') [11], and 3 tests with MDF panels ('MM1', 'MM2' and 'MM3') [12]. As shown in Fig. 1, the test panels in the SBI tests were $1.5 \mathrm{~m}$ high. The long panel is $1.0 \mathrm{~m}$ wide, and the short panel is $0.5 \mathrm{~m}$ wide. Conditioning of the panels was done prior to the tests at $294 \mathrm{~K}$ and $50 \%$ relative humidity. The fire source was a triangular propane sandstone burner with side dimension of $0.25 \mathrm{~m}$, located at a $0.04 \mathrm{~m}$ clearance from the panels. After ignition $(t=0 \mathrm{~s})$, it took approximately $30 \mathrm{~s}$ for the burner to reach its peak HRR of $30 \mathrm{~kW}$ [11]. Simulations consider the same $30 \mathrm{~s}$ HRR ramp for the burner by adjusting the mass flow rate of the propane (see Table 1). The heat of combustion of propane is set to $46.5 \mathrm{MJ} / \mathrm{kg}$ [16]. The simulations consider complete combustion of the propane gas, because possible combustion inefficiency is already embedded in the mass flow rate of propane, as it corresponds with the experimental HRR [11], obtained from 
oxygen calorimetry. The heat flux measurements in the experiments are made using the sensors illustrated in Fig. 1, and pyrolysis fronts are visually tracked in the footage, considering the front to be at the outermost location at which MDF material has pyrolyzed and charred [11]. Only the first 900 s of the experiments are considered, during which the fire did not penetrate through the MDF panels [12].

Table 1: The HRR ramp of the propane burner in the experiments $[11,12]$ and the corresponding mass flow rate of propane in the simulations. The heat of combustion of propane is considered to be $46.45 \mathrm{MJ} / \mathrm{kg}$ [16].

\begin{tabular}{ccc}
\hline Time $(\mathbf{s})$ & $\begin{array}{c}\text { Burner HRR in the } \\
\text { experiments }[\mathbf{1 1}, \mathbf{1 2}] \mathbf{( k W})\end{array}$ & $\begin{array}{c}\text { Burner propane flow rate } \\
\text { in the simulations }(\mathbf{k g} / \mathbf{s})\end{array}$ \\
\hline 0 & 0 & 0 \\
3 & 12.9 & $2.777 \times 10^{-4}$ \\
6 & 20.5 & $4.414 \times 10^{-4}$ \\
9 & 25.8 & $5.555 \times 10^{-4}$ \\
12 & 27.8 & $5.985 \times 10^{-4}$ \\
15 & 28.5 & $6.136 \times 10^{-4}$ \\
18 & 28.8 & $6.200 \times 10^{-4}$ \\
21 & 29.1 & $6.265 \times 10^{-4}$ \\
24 & 29.5 & $6.351 \times 10^{-4}$ \\
27 & 29.8 & $6.416 \times 10^{-4}$ \\
30 & 30.0 & $6.459 \times 10^{-4}$ \\
900 & 30.0 & $6.459 \times 10^{-4}$ \\
\hline
\end{tabular}

\subsection{Material properties}

The material properties of the sample CS and MDF panels $(0.0123 \mathrm{~m}$ and $0.0184 \mathrm{~m}$ thick, respectively) are presented in Tables 2 and 3. Several model-effective properties of the MDF material, necessary for the simulations, were obtained in [17] based on several FPA pyrolysis tests conducted in a controlled nitrogen atmosphere at radiative heat fluxes ranging from 25 to 100 $\mathrm{kW} / \mathrm{m}^{2}$. This involved an inverse modeling approach [18] making use of the 
Table 2: Model-effective material properties of CS panels in test CSCS [11]

\begin{tabular}{lc}
\hline Property & Value \\
\hline$\rho\left[\mathrm{kg} \cdot \mathrm{m}^{-3}\right]$ & $1005 \pm 5 \%$ \\
$c_{p}\left[\mathrm{~J} \cdot \mathrm{kg}^{-1} \cdot \mathrm{K}^{-1}\right]$ & 920 \\
$\lambda\left[\mathrm{W} \cdot \mathrm{m}^{-1} \cdot \mathrm{K}^{-1}\right]$ & 0.17 \\
$a_{\text {eff }}[-]$ & $0.9^{a}$ \\
$\varepsilon_{\text {eff }}[-]$ & $0.9^{a}$ \\
\hline
\end{tabular}

${ }^{a}$ Default panel radiation properties, as in [19, 20].

1D pyrolysis model embedded in FireFOAM [14]. Accordingly, two separate sets of material properties were estimated. The Uniform Density (UD) set assumes MDF material with uniform through-thickness density, while the Non-uniform Density (ND) set assumes MDF material with a non-uniform through-thickness density profile. These two sets of model-effective material properties have been presented in Table 3 .

The ND through-thickness density profile, i.e., $\rho(Z)\left(\mathrm{kg} / \mathrm{m}^{3}\right)$, is assumed parabolic, in consistence with the literature $[1,2]$ :

$$
\rho(Z)=\rho_{b u l k} \cdot\left\{1+\frac{1-\xi}{2+\xi}\left[1-12\left(\frac{Z}{L}\right)^{2}\right]\right\}
$$

where $Z$ denotes the through-thickness distance from the center of the panel in meter (ranging between -0.0092 and $0.0092 \mathrm{~m}$ ), $\rho_{\text {bulk }}$ is the bulk density $\left(605 \mathrm{~kg} / \mathrm{m}^{3}\right), L$ is the thickness of the MDF panels in meters, and $\xi$ is the ratio of maximum density at panel surface to the minimum density midway through the thickness. The ratio $\xi$ has been considered as an optimization parameter in [17] and has been estimated to be 1.61, well in line with values reported in the literature, ranging between 1.50 and 1.75 [2]. Note that the ND bulk density equals the UD value, i.e., $605 \mathrm{~kg} / \mathrm{m}^{3}$ (see Fig. 2). 
Table 3: Material properties of the sample MDF panels in tests MM1 to MM3 [12]

\begin{tabular}{lcc}
\hline Property & Uniform density (UD) set & Non-uniform density (ND) set \\
\hline$\rho_{v}\left[\mathrm{~kg} \cdot \mathrm{m}^{-3}\right]$ & 605 & $\rho(Z)^{a, b}$ \\
$\rho_{c}\left[\mathrm{~kg} \cdot \mathrm{m}^{-3}\right]$ & $133^{b, c}$ & $133^{b, c}$ \\
$a_{e f f, v}[-]$ & $0.70^{d}$ & $0.70^{d}$ \\
$a_{\text {eff,c }}[-]$ & $0.86^{e}$ & $0.86^{e}$ \\
$\varepsilon_{e f f, v}[-]$ & $0.70^{d}$ & $0.70^{d}$ \\
$\varepsilon_{e f f, c}[-]$ & $0.86^{e}$ & $0.86^{e}$ \\
$c_{p, v}\left[\mathrm{~J} \cdot \mathrm{kg}^{-1} \cdot \mathrm{K}^{-1}\right]$ & $1580^{b}$ & $1576^{b}$ \\
$c_{p, c}\left[\mathrm{~J} \cdot \mathrm{kg}^{-1} \cdot \mathrm{K}^{-1}\right]$ & $1450^{f}$ & $1450^{f}$ \\
$\lambda_{v}\left[\mathrm{~W} \cdot \mathrm{m}^{-1} \cdot \mathrm{K}^{-1}\right]$ & $0.18^{b}$ & $0.18^{b}$ \\
$\lambda_{c}\left[\mathrm{~W} \cdot \mathrm{m}^{-1} \cdot \mathrm{K}^{-1}\right]$ & $0.21^{b}$ & $0.18^{b}$ \\
$\Delta H_{p y r o l}\left[\mathrm{~J} \cdot \mathrm{kg}^{-1}\right]$ & $9.54 \times 10^{6 b, g}$ & $9.54 \times 10^{6 b, g}$ \\
$n[-]$ & $0.66^{b, h}$ & $1.04^{b, h}$ \\
$A\left[\mathrm{~s}^{-1}\right]$ & $1.47 \times 10^{4 b, h}$ & $9.03 \times 10^{4 b, h}$ \\
$E_{a}\left[\mathrm{~J} \cdot \mathrm{mol}^{-1}\right]$ & $7.19 \times 10^{4 b, h}$ & $8.02 \times 10^{4 b, h}$ \\
$H_{p y r}\left[\mathrm{~J} \cdot \mathrm{kg}^{-1}\right]$ & $1.05 \times 10^{5 b, h, i}$ & $-1.02 \times 10^{4 b, h, i}$ \\
\hline$a$
\end{tabular}

${ }^{a}$ Refer to Eq. (1).

${ }^{\boldsymbol{b}}$ Model-effective property estimated in [17] based on inverse modeling of FPA tests in nitrogen.

${ }^{c}$ Refer to text for explanation regarding the estimation of $\rho_{c}$.

$\boldsymbol{d}$ The emissivity and absorptivity were determined to be temperature dependent, as quantified in [17], but an average value is used here based on the spectral range of infrared heaters of FPA.

$\boldsymbol{e}$ Relatively constant in the temperature range between 300 and $3000 \mathrm{~K}$, as established by the spectral measurements made using spectrophotometers [17].

${ }^{f}$ Specific heat capacity of graphite (carbon) at average surface temperatures of a pyrolyzing sample $[21]$.

${ }^{g}$ Available from the FPA combustion test performed under $50 \mathrm{~kW} / \mathrm{m}^{2}$.

${ }^{h}$ Reaction kinetic parameter for the pyrolysis reaction: Virgin $\longrightarrow$ Char + Pyrolyzate.

${ }^{i}$ A positive value denotes an endothermic reaction. Note that both endothermic and exothermic reactions are expectable $[22]$. 


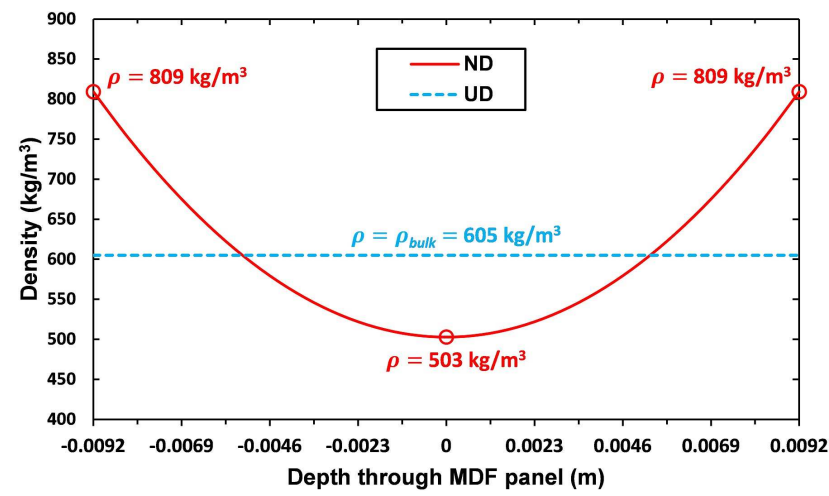

Figure 2: Distribution of mass density through the thickness of the MDF panels in the UD and ND cases presented in Table 3. Note that the bulk density is the same for both the cases. Depths $0.0092 \mathrm{~m}$ and $0.0092 \mathrm{~m}$ correspond to the back and front surfaces of the panels, respectively.

It is noteworthy that implementation of a non-uniform mass density distribution through the thickness of the panels also implies non-uniform heating, because the heat transfer through the material is governed by the coupled effect of material thermal conductivity, density, and specific heat capacity, due to the role of thermal diffusivity. Nevertheless, to the best of the authors' knowledge, no literature data is available regarding the variation patterns of thermal conductivity and specific heat capacity across the thickness of MDF panels, with a distinctive profile similar to that of density as characterized in $[1,2]$. Hence, we only consider the estimated non-uniform distribution of density as discussed above, along with a uniform thermal conductivity and a uniform specific heat capacity.

The density of char, $\rho_{c}$, as estimated in [17], shows optimum values of 125 and $142 \mathrm{~kg} / \mathrm{m}^{3}$ for the UD and ND sets, respectively. For the simulations discussed here, an identical $\rho_{c}$ value is considered for both the UD and ND sets, namely $133 \mathrm{~kg} / \mathrm{m}^{3}$, which is the average of the aforementioned optimum 
values. The reason for this is as follows: the total heat of combustion in the MDF panels per unit volume is $\rho_{v}$, bulk $\cdot \Delta H_{\text {tot }}$, with $\rho_{v, \text { bulk }}\left(605 \mathrm{~kg} / \mathrm{m}^{3}\right)$ being the bulk density of virgin MDF and $\Delta H_{t o t}$ the total heat of combustion of MDF. In the pyrolysis model $[13,14]$, this is decomposed as:

$$
\rho_{v, \text { bulk }} \cdot \Delta H_{\text {tot }}=\left(\rho_{v, \text { bulk }}-\rho_{c}\right) \cdot \Delta H_{\text {pyrol }}+\rho_{c} \cdot \Delta H_{c}
$$

The first term on the right-hand side corresponds to pyrolyzate, with $\Delta H_{\text {pyrol }}$ being the heat of combustion of MDF pyrolyzate $(\mathrm{J} / \mathrm{kg})$. The second term corresponds to char, with $\Delta H_{c}$ being the heat of combustion of MDF char (set to $32.8 \times 10^{6} \mathrm{~J} / \mathrm{kg}$ in FireFOAM). Making $\rho_{c}$ equal for the UD and ND cases ensures that the same amount of energy is released per unit volume of pyrolyzate, as both cases have the same value of $\Delta H_{\text {tot }}$ (chosen such that the value of $\Delta H_{\text {pyrol }}$ corresponds to that given in Table 3).

\section{Numerical modeling}

The simulations are performed using FireFOAM version 2.2.x [13, 14]. FireFOAM is an unsteady solver for buoyancy driven turbulent reacting flows based on a $\mathrm{C}++$ code that employs the Open-FOAM platform [15]. The FireFOAM code solves for the NavierStokes equations using a Favre-filtered fully compressible flow formulation. In addition, transport equations are considered for species mass fractions and sensible enthalpy as in [23]. The diffusivity of different species is assumed to be equal. Thus, only the thermal diffusivity is computed, as it is expected to be more important than mass diffusivity in the case of fire simulations. A Pressure-Implicit Split-Operator (PISO) algorithm is used for the pressure-velocity coupling with a RhieChow 
interpolation to avoid odd-even decoupling, and all quantities are assigned to the cell centers (collocated grid) with velocities linearly interpolated to the cell faces.

A maximum Courant number of 0.9 is used for time-marching in the calculations, following a first order semi-implicit Euler scheme, and the turbulent Lewis number is considered to be equal to unity. The convective terms are second order centrally differenced. For scalar transport, a second order Total Variation Diminishing (TVD) scheme is applied using a Sweby limiter while the diffusive terms are centrally differenced and corrected for the non-orthogonality of the mesh. The pressure equation is solved by a linear Geometric-algebraic multi-grid (GAMG) solver, and the momentum and species equations are solved using a Preconditioned Bi-Conjugate Gradient (PBiCG) scheme.

\subsection{Pyrolysis}

The default sub-model for pyrolysis in FireFOAM 2.2.x $[13,14]$ is applied, assuming a single-step decomposition of the MDF material:

$$
\text { Virgin } \longrightarrow \text { Char + pyrolyzate }
$$

This approach does not directly consider moisture evaporation [24], nor char oxidation [25]. Their related influence is incorporated in the estimation of material properties from the FPA tests (see Table 3). In particular, the uncertainty in char oxidation modeling is circumvented through an effective heat of combustion based on the FPA combustion test (see section 2.1), accounting for the minor char oxidation that occurs during the experiment. 


\subsection{Combustion}

The eddy dissipation combustion model (EDM) [26] is implemented, as in [27], but the default FireFOAM combustion model yields very similar results (not discussed here for brevity), suggesting that the heat transfer and pyrolysis modeling are dominant for the problem at hand.

The combustion model employs a one-step, infinitely fast, irreversible chemical reaction, computing the fuel mass reaction rate $\overline{\dot{\omega}}_{F}^{\prime \prime \prime}\left(\mathrm{kg} / \mathrm{m}^{3} . \mathrm{s}\right)$ as:

$$
\overline{\dot{\omega}_{F}^{\prime \prime \prime}}=\bar{\rho} \cdot \frac{\min \left(\widetilde{Y}_{F}, \widetilde{Y}_{O_{2}} / r\right)}{\tau_{m i x}}
$$

where $\widetilde{Y}_{F}$ and $\widetilde{Y}_{\mathrm{O}_{2}}$ are Favre-filtered mass fractions of the fuel (propane) and oxygen, respectively, $r$ is the stoichiometric ratio of fuel to oxygen by mass, and $\tau_{m i x}(\mathrm{~s})$ is the reaction time scale in the gas phase, considering the chemical time scale and the mixing times required for diffusion, sub-grid scale advection, and buoyant acceleration, as discussed in detail in [27].

\subsection{Turbulence}

The LES approach is adopted with the dynamic Smagorinsky model [28], with a turbulent Prandtl number of 0.7, although no significant influence from Prandtl number was observed when it was varied between 0.5 and 1.0 in a sensitivity analysis [29]. The sub-grid scale viscosity, $\mu_{s g s}(\mathrm{~kg} / \mathrm{m} . \mathrm{s})$, is computed as:

$$
\mu_{\text {sgs }}=\bar{\rho}_{\text {gas }} \cdot\left(c_{s} \Delta\right)^{2} \cdot|\widetilde{S}|
$$


where $\bar{\rho}_{\text {gas }}$ is the Reynolds averaged mean gas density in the computational cell $\left(\mathrm{kg} / \mathrm{m}^{3}\right), c_{s}$ is a model parameter computed dynamically and varying locally in time and space, $\Delta$ is the LES filter size (m), taken as $\Delta=(\Delta x \cdot \Delta y \cdot \Delta z)^{1 / 3}$ with $\Delta x, \Delta y$ and $\Delta z$ denoting the effective grid spacing in different coordinate directions, and $\widetilde{S}(1 / \mathrm{s})$ is the Favre-filtered strain rate tensor. Near the walls, a default turbulent viscosity boundary condition for rough walls is applied using the Spalding's law based on velocity [30, 14], considering also the blowing effect based on the pyrolyzate mass flux (section $3.5)$.

The sub-grid scale kinetic energy, $k_{s g s}\left(\mathrm{~m}^{2} / \mathrm{s}^{2}\right)$, is computed as:

$$
k_{s g s}=c_{I} \cdot \Delta^{2} \cdot|\widetilde{S}|^{2}
$$

where $c_{I}$ is a model parameter computed dynamically. In our implementation in FireFOAM, the coefficients $c_{s}$ and $c_{I}$ in Eqs. (5) and (6) are computed as local averages of their face values. Correspondingly, the negative values of the sub-grid viscosity are clipped to zero to avoid numerical instabilities while a simple top-hat filter is used as a test filter, implemented as a surface integral of the face interpolate of the field. On all the walls, a zero gradient condition is applied.

The dynamic viscosity, $\mu(\mathrm{kg} / \mathrm{m} . \mathrm{s})$, is computed from Sutherland's law [31]. The molecular thermal diffusivity, $\alpha\left(\mathrm{m}^{2} / \mathrm{s}\right)$, is expressed as $\lambda_{\text {gas }} / \rho_{\text {gas }} \cdot c_{p}$, where $\lambda_{\text {gas }}$ is the thermal conductivity of the gaseous species (W/m.K) determined from the Eucken model [32], $\rho_{\text {gas }}$ is the gas density $\left(\mathrm{kg} / \mathrm{m}^{3}\right)$, and $c_{p}$ is the specific heat capacity $(\mathrm{J} / \mathrm{kg} . \mathrm{K})$ determined based on the 7 -coefficient NASA polynomials in the Burcat database [33] as a function of temperature. 


\subsection{Radiation}

The Finite volume Discrete Ordinates Model (fvDOM) is used to solver for Radiative Transfer Equation (RTE) in FireFOAM, such that the radiation intensity is treated as a function of both spatial location and angular direction, with a total of 48 angles $(3 \times 4$ azimuthal and 4 polar angles), as in [34]. An optically-thin assumption is made and the radiative emission is modeled using a radiant-fraction based approach, where a portion of the chemical HRR is converted to radiation, as expressed below:

$$
\nabla \cdot \overline{\dot{q}_{r a d}^{\prime \prime}}=\chi_{r a d} \cdot \overline{\dot{q}_{c o m b}^{\prime \prime \prime}}
$$

where $\overline{\dot{q}_{r a d}^{\prime \prime}}$ is the radiative heat flux $\left(\mathrm{W} / \mathrm{m}^{2}\right), \chi_{\text {rad }}$ is the global radiant fraction

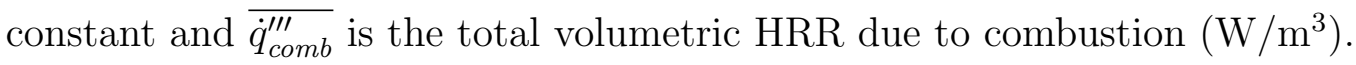
Accordingly, the $\chi_{\text {rad }}$ parameter in Eq. (7) is determined based on the respective radiant fraction of HRR from the burner, i.e., $\chi_{\text {rad, burner }}$, and the radiant fraction of HRR from the MDF panels, i.e., $\chi_{\text {rad, panel }}$, as follows:

$$
\chi_{\text {rad }}=\frac{\dot{m}_{\text {burner }}^{\prime \prime} \cdot \chi_{\text {rad, burner }}+\dot{m}_{\text {panel }}^{\prime \prime} \cdot \chi_{\text {rad, panel }}}{\dot{m}_{\text {burner }}^{\prime \prime}+\dot{m}_{\text {panel }}^{\prime \prime}}
$$

where $\dot{m}_{\text {burner }}^{\prime \prime}$ is the mass flow rate of propane from the burner $(\mathrm{kg} / \mathrm{s})$, and $\dot{m}_{\text {panel }}^{\prime \prime}$ is the rate of mass loss from the panels in terms of propane $(\mathrm{kg} / \mathrm{s})$ :

$$
\dot{m}_{\text {panel }}^{\prime \prime}=\dot{m}_{\text {pyrol }}^{\prime \prime} \cdot \Delta H_{\text {pyrol }} / \Delta H_{\text {propane }}
$$

where $\dot{m}_{\text {pyrol }}^{\prime \prime}$ is pyrolyzate mass flux from the MDF panels $(\mathrm{kg} / \mathrm{s}), \Delta H_{\text {pyrol }}$ is the heat of combustion of MDF pyrolyzate given in Table 3 , and $\Delta H_{\text {propane }}$ 
is the heat of combustion of propane $(46.45 \mathrm{MJ} / \mathrm{kg})$. Hence, the combustion in the gas phase is treated as complete combustion of propane gas via the reaction $\mathrm{C}_{3} \mathrm{H}_{8}+5 \mathrm{O}_{2}+18.8 \mathrm{~N}_{2} \longrightarrow 3 \mathrm{CO}_{2}+4 \mathrm{H}_{2} \mathrm{O}+18.8 \mathrm{~N}_{2}$. Nevertheless, the combustion inefficiency is already embedded within the definition of $\Delta H_{\text {pyrol }}$ as well as within the regulated propane flow rate of the burner, as discussed in explanations for Eq. (2) and Table 1, respectively. This simple, yet effective, radiation modeling approach avoids the uncertainties related to the modeling of turbulence-radiation interaction (TRI) and modeling of soot and soot radiation. Moreover, it aims to minimize the effect from the dependency of the source term of the RTE on the filtered temperature, $\widetilde{T}^{4}$, that can lead to significant errors in the calculations if coarse grids are employed in the numerical simulations. $\chi_{\text {rad, panel }}$ is fixed at 0.33 for the MDF panels. This radiant fraction value correlates with the radiant fraction of wood products in the literature [35]. Note that the base material of the sample MDF panels is softwood, with a typical radiant fraction ranging from 0.30 for pine wood to 0.38 for Douglas fir [35]. Based on experimental observations of propane gaseous pool fires [36], an upper limit value of 0.3 is expected for $\chi_{\text {rad, burner }}$. The adequacy of this radiant fraction value has been assessed here through a simulation case corresponding to test CSCS [11]. There is no flame spread on the panels in this case, allowing to evaluate the total heat fluxes from the burner itself (section 4.1.2).

\subsection{Convection}

At the backside of the panels, natural convection is considered with a convective heat transfer coefficient of $20 \mathrm{~W} /\left(\mathrm{m}^{2} . \mathrm{K}\right)$. On the front side, capturing the appropriate convection requires a very fine mesh resolution near 
the surface of the walls, on the order of $0.003 \mathrm{~m}$ [37], because the convective heat fluxes remain approximately constant with elevation, but decrease with the pyrolyzate mass flux [37]. This is known as the 'blowing effect' [38]. In the present study, we bypass the need for a very fine mesh near the walls by accounting for the blowing effect using an empirical wall function developed by Wang et al. [39]. Accordingly, when the panels are cooling down (i.e., $\left.T_{\text {panel }}>T_{\text {gas }}\right)$, the convection is taken to be equal to $\dot{q}_{c o n v, l a m}^{\prime \prime}=-\alpha \cdot \rho \cdot c_{p} \cdot \frac{\partial T}{\partial s}$, where $\dot{q}_{c o n v, ~ l a m}^{\prime \prime}$ is the convective heat flux based on the molecular thermal diffusivity, and $s$ denotes the Cartesian ordinate normal to the surface of the pyrolyzing surface $(\mathrm{m})$. Whenever the panels are heating up (i.e., $T_{\text {gas }}>T_{\text {panel }}$ ):

- when $\dot{m}_{\text {pyrol }}^{\prime \prime}<10^{-4} \mathrm{~kg} / \mathrm{m}^{2}$.s:

$$
\dot{q}_{c o n v}^{\prime \prime}=\frac{\min \left(\max \left(0, \dot{q}_{c o n v, \text { lam }}^{\prime \prime}\right), \dot{q}_{c o n v, \text { thresh }}^{\prime \prime}\right)}{\dot{q}_{c o n v, \text { thresh }}^{\prime \prime}} \cdot \dot{q}_{c o n v, \text { flam }}^{\prime \prime}
$$

- when $\dot{m}_{\text {pyrol }}^{\prime \prime} \geq 10^{-4} \mathrm{~kg} / \mathrm{m}^{2} . \mathrm{s}$ :

$$
\dot{q}_{c o n v}^{\prime \prime}=\dot{q}_{c o n v, f l a m}^{\prime \prime} \cdot\left[\frac{\dot{m}_{\text {pyrol }}^{\prime \prime} / h_{m}}{\exp \left(\dot{m}_{\text {pyrol }}^{\prime \prime} / h_{m}\right)-1}\right]
$$

where $\dot{q}_{c o n v}^{\prime \prime}$ is the computed convective heat flux on the panels with mass transfer $\left(\mathrm{W} / \mathrm{m}^{2}\right) ; \dot{q}_{\text {conv, flam }}^{\prime \prime}$ is the upper limit for turbulent convective heating without mass transfer, taken as $14000 \mathrm{~W} / \mathrm{m}^{2}$, estimated by assuming a temperature difference between the surface and the gas phase of approximately $900950 \mathrm{~K}$ (considered not to change significantly along the height of the panels $) ; h_{m}\left(\mathrm{~kg} / \mathrm{m}^{2} . \mathrm{s}\right)$ is the mass transfer coefficient, estimated as 0.01 $\mathrm{kg} / \mathrm{m}^{2}$.s based on [40]; and $\dot{q}_{\text {conv, thresh }}^{\prime \prime}=500 \mathrm{~W} / \mathrm{m}^{2}$ is a threshold parameter. 
Eq. (11) accounts for the blowing effects that are significant at mass flow rates higher than $10^{-4} \mathrm{~kg} \cdot \mathrm{m}^{2} / \mathrm{s}$. When the pyrolyzate mass flow is below $10^{-4} \mathrm{~kg} \cdot \mathrm{m}^{2} / \mathrm{s}$, Eq. (10) is used to account for the convective heat transfer based on the molecular thermal diffusivity parameter. Whenever $\dot{q}_{\text {conv, lam }}^{\prime \prime}$ is below the threshold value $\dot{q}_{c o n v}^{\prime \prime}$, thresh, the convective heat flux is taken to be a

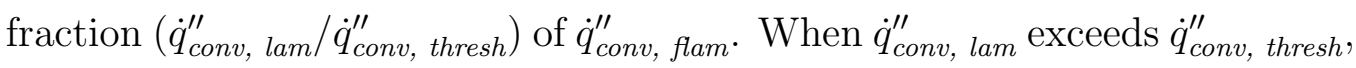
the fraction is adjusted to unity. The benefit of this wall function is that the convective heat fluxes are not strongly grid-dependent when relatively coarser grids are used in the numerical simulations.

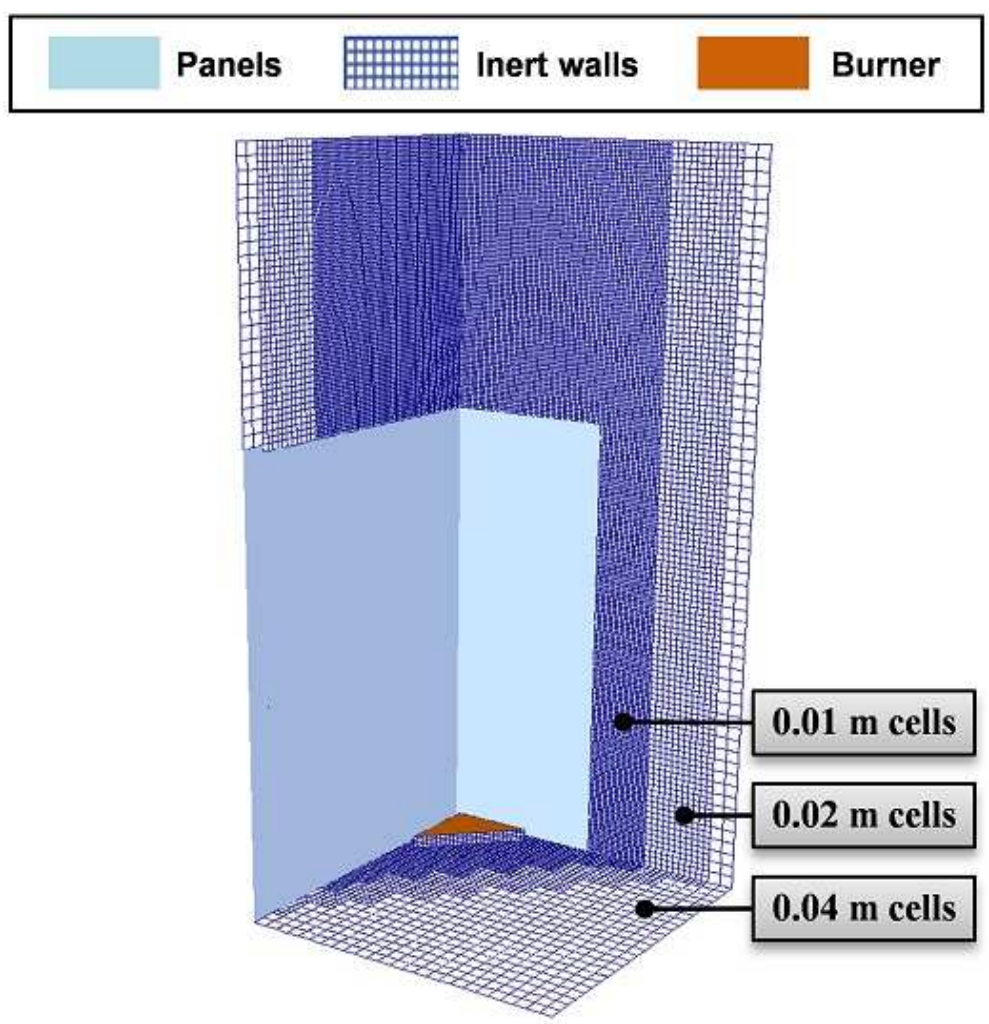

Figure 3: The set-up of the simulations $(1 \mathrm{~m} \times 1 \mathrm{~m} \times 2.4 \mathrm{~m})$ : the mesh features local refinements with $0.01 \mathrm{~m}$ cells near the corner and 0.02 and $0.04 \mathrm{~m}$ cells further away. 
Table 4: Simulation cases considered in the computational analysis. The panel density distribution profiles are provided in Table 2 and 3.

\begin{tabular}{lccc}
\hline & CS1 & ND1 & UD1 \\
\hline Panel density & Uniform & Non-uniform & Uniform \\
Gas phase cells & 603,300 & 603,300 & 603,300 \\
Solid phase cells & 567,030 & 850,545 & 850,545 \\
Total no. of cells & $1,170,330$ & $1,453,845$ & $1,453,845$ \\
Run time (h) & $112.1^{a}$ & $426.6^{b}$ & $418.8^{b}$ \\
\hline
\end{tabular}

${ }^{a}$ Run time on an Intel machine with 20 cores (Xeon E5-2680v2, $2.8 \mathrm{GHz}$ CPUs).

${ }^{\boldsymbol{b}}$ Run time on an Intel machine with 24 cores (Xeon E5-2680v3, $2.5 \mathrm{GHz} \mathrm{CPUs})$.

\subsection{Computational set-up and simulation cases}

As shown in Fig. 3, the computational mesh features local refinements with cell sizes as small as $0.01 \mathrm{~m}$. A total of 3 simulations are discussed here, including 1 case with CS panels (' $C S 1$ '), and 2 cases with MDF panels, i.e., non-uniform density case ' $N D 1$ ' and uniform density case 'UD1', with details described in Table 4.

The triangular burner has been created using hexahedra and split-hexahedra meshes from a triangulated surface geometry in Stereolithographic (STL) format by means of a default OpenFOAM utility [41].

In the MDF simulations, 45 cells are considered across the thickness of the panels (thus each cell is approximately $0.00041 \mathrm{~m}$ thick), resulting in a fine distribution of density, featuring less than $0.7 \%$ difference between UD and ND simulations in terms of total MDF material mass. For CS1, 35 cells are considered through the thickness (thus each cell is approximately 0.00035 
m thick). This provides a cell size smaller than the square root of material diffusivity, ensuring a low error term in the Euler time integration scheme, as implemented in [20]. At the boundary between the solid and the gas phase, the cells are mapped onto each other. Details of the default solid-gas phase coupling and models are described in [18, 21, 37].

For the flow field, an open boundary condition is assumed at the top of the domain, considering a zero normal gradient condition when the flow is outward and a fixed value when the flow is inward. Similarly, an open boundary condition is assumed at the sides of the domain, considering a zero normal gradient condition on all components, except where there is inflow, in which case a fixed value condition is applied to the tangential component. On the inert walls, a no-slip condition is applied. Definitions of these open boundary and zero normal gradient conditions are available in OpenFOAM $[42]$.

\section{Results and discussion}

The key simulation results are discussed in this section, while supplementary material is made available online on grid and wall function sensitivity, as well as panel backside temperatures and char formation evolution.

\subsection{Inert CS panel case}

First we discuss the results of case CS1 in comparison with test 'CSCS' of [11]. There is no flame spread on the panels, allowing to assess the predicted flame height and heat fluxes of the burner itself.

Figure 4 provides a visualization of the corner fire at $t=180 \mathrm{~s}$, along with a corresponding footage snapshot from test CSCS [11]. In both the 
simulation and the experiment [11], sensor S1 is in the persistent flame zone where it is engulfed by the flames constantly, whereas sensor S3 is in the intermittent flame zone where it is touched by the flames irregularly, and sensor $\mathrm{S} 2$ is located furthest away from the fire, where the flame presence is not frequent.
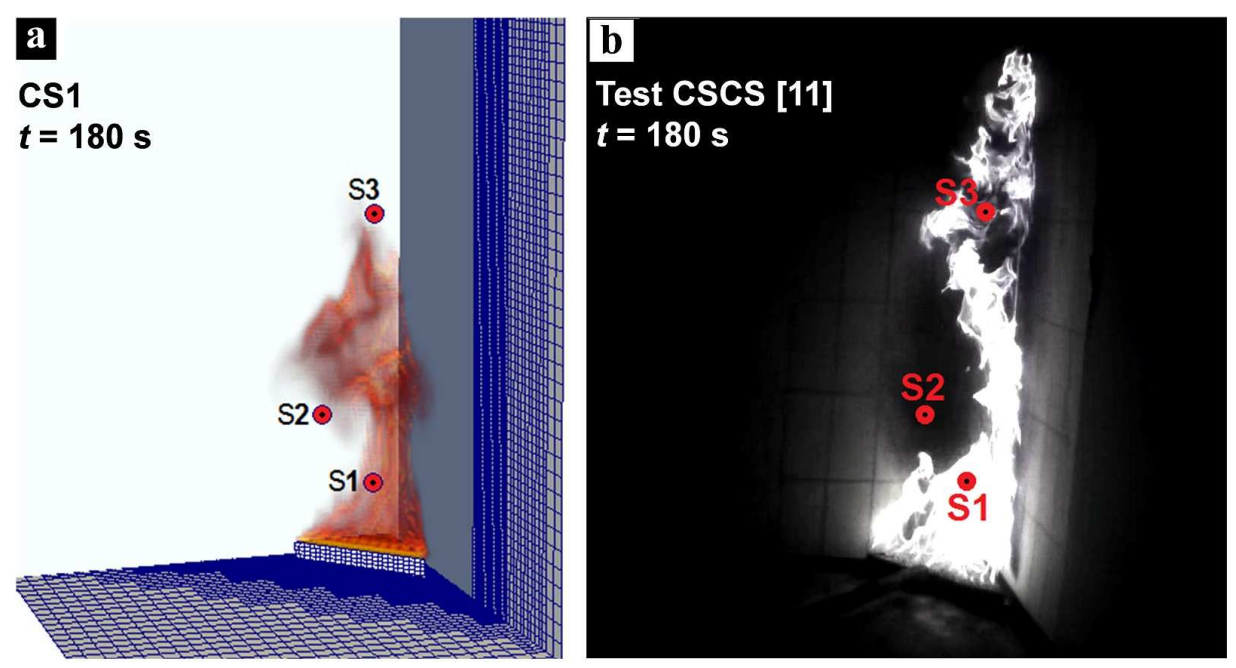

Figure 4: The visualization of the corner fire from (a) FireFOAM simulation CS1 and (b) a footage from the experimental test CSCS [11]: see Fig. 1 for the locations of heat flux sensors S1 to S3 ( Note that only sensor S1 is in the persistent flame zone.

\subsubsection{Flame heights}

Various parameters can serve as indicators of flame height, such as mixture fraction, intermittency of flames, gas temperatures, or HRR per unit volume. In absence of substantial transient fire growth, a 'mean flame height' is conventionally defined as the distance above the fire source where the intermittency of the flames is $50 \%$ [43]. As our main simulations (with MDF panels) involve fire growth, instantaneous flame heights are determined in 
this study through HRR integration in the computational domain. Accordingly, the flame height is defined as the height below which the integrated HRR is $95 \%$ of the total HRR [44].

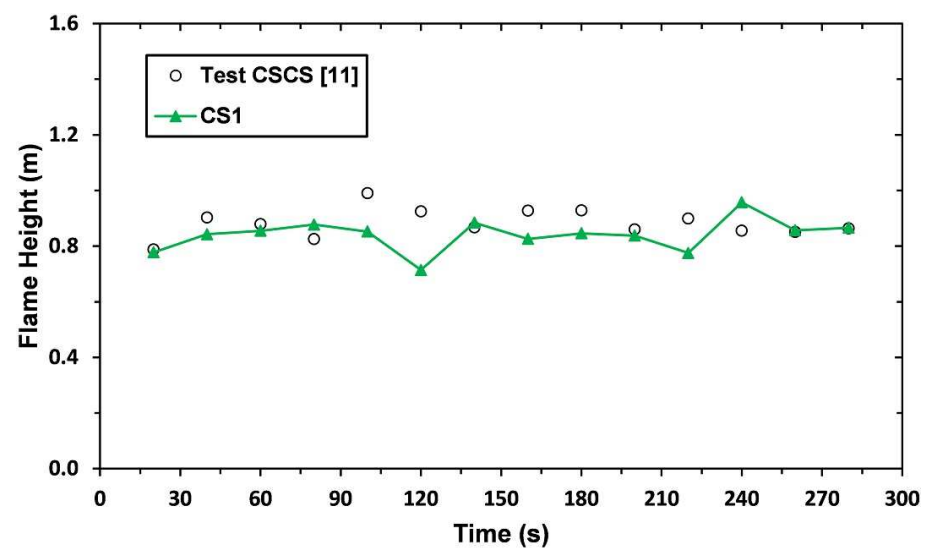

Figure 5: The flame heights in simulation CS1 versus those in test CSCS [11]: an averaging period of $2 \mathrm{~s}$ is considered, as in [11], with a time resolution of $0.01 \mathrm{~s}$.

The flame height results are shown in Fig. 5. The predictions are very satisfactory considering the relatively complex shape of the burner, i.e., triangular, along with the fairly challenging geometry, namely close to a corner of walls. The predicted mean flame height in simulation CS1, $0.84 \mathrm{~m}$., is within $4 \%$ of the experimental value $(0.87 \mathrm{~m})$ [11].

\subsubsection{Total heat fluxes}

In order to compare the heat flux exposure, it is first essential to appreciate the nature of heat flux as recorded by Schmidt-Boelter gauges, hereafter referred to as 'total gauge heat flux,' i.e. $\dot{q}_{\text {gauge }}^{\prime \prime}\left(\mathrm{W} / \mathrm{m}^{2}\right)$. In principle, $\dot{q}_{\text {gauge }}^{\prime \prime}$ consists of two distinct parts, namely the net radiation absorbed by the 
gauge, i.e. $\dot{q}_{\text {rad, gauge }}^{\prime \prime}\left(\mathrm{W} / \mathrm{m}^{2}\right)$, and the convection absorbed by the gauge, i.e. $\dot{q}_{\text {conv, gauge }}^{\prime \prime}\left(\mathrm{W} / \mathrm{m}^{2}\right)$ :

$$
\begin{aligned}
\dot{q}_{\text {gauge }}^{\prime \prime} & =\dot{q}_{\text {rad, gauge }}^{\prime \prime}+\dot{q}_{\text {conv, gauge }}^{\prime \prime} \\
& =\left(\alpha_{\text {gauge }} \cdot \dot{q}_{\text {inc }}^{\prime \prime}-\sigma \cdot \varepsilon_{\text {gauge }} \cdot T_{\text {gauge }}^{4}\right)+h \cdot\left(T_{\text {gas }}-T_{\text {gauge }}\right)
\end{aligned}
$$

where $\alpha_{\text {gauge }}$ and $\varepsilon_{\text {gauge }}$ are the absorptivity and emissivity of the gauge (taken to be equal to unity, as the gauge is typically approximated as a black body [45]), $T_{\text {gauge }}$ is the temperature of the gauge (equal to $323 \mathrm{~K}$ at which the gauge is constantly water cooled $[11,12]), \dot{q}_{i n c}^{\prime \prime}$ is the net incident radiation $\left(\mathrm{W} / \mathrm{m}^{2}\right), \sigma$ is the Stefan-Boltzmann constant $\left(5.67 \times 10^{-8} \mathrm{~W} / \mathrm{m}^{2} \mathrm{~K}^{4}\right), h$ is the convective heat transfer coefficient $\left(\mathrm{W} / \mathrm{m}^{2} \mathrm{~K}\right)$, and $T_{\text {gas }}$ is the gas temperature $(\mathrm{K})$. By adding and subtracting $h \cdot T_{\text {panel }}$, where $T_{\text {panel }}$ is the panel temperature (K), one can rewrite Eq. (12) as follows:

$$
\dot{q}_{\text {gauge }}^{\prime \prime}=\dot{q}_{i n c}^{\prime \prime}-\sigma \cdot T_{\text {gauge }}^{4}+h \cdot\left(T_{\text {gas }}-T_{\text {panel }}\right)+h \cdot\left(T_{\text {panel }}-T_{\text {gauge }}\right)
$$

where $h \cdot\left(T_{\text {gas }}-T_{\text {panel }}\right)$ is simply the convective heat transfer to the panel, i.e. $\dot{q}_{c o n v, \text { panel }}^{\prime \prime}\left(\mathrm{W} / \mathrm{m}^{2}\right)$. Therefore Eq. (13) can be expressed as:

$$
\dot{q}_{\text {gauge }}^{\prime \prime}=\dot{q}_{\text {inc }}^{\prime \prime}-\sigma \cdot T_{\text {gauge }}^{4}+\dot{q}_{\text {conv, panel }}^{\prime \prime}+h \cdot\left(T_{\text {panel }}-T_{\text {gauge }}\right)
$$

Hence, $\dot{q}_{\text {gauge }}^{\prime \prime}$ can be calculated using Eq. (14) and be compared with the experimentally reported gauge heat fluxes $[11,12]$, considering that $\dot{q}_{i n c}^{\prime \prime}$, $\dot{q}_{c o n v, p a n e l}^{\prime \prime}$, and $T_{\text {panel }}$ are predicted in the simulations, and the other parameters are: $\sigma=5.67 \times 10^{-8} \mathrm{~W} / \mathrm{m}^{2} \mathrm{~K}^{4}, h \approx 15 \mathrm{~W} / \mathrm{m}^{2} \mathrm{~K}$, and $T_{\text {gauge }}=323 \mathrm{~K}$.

The evolution profiles of total gauge heat fluxes in the simulation CS1, determined according to the definition in Eq. (14), are shown in Fig. 6 along 

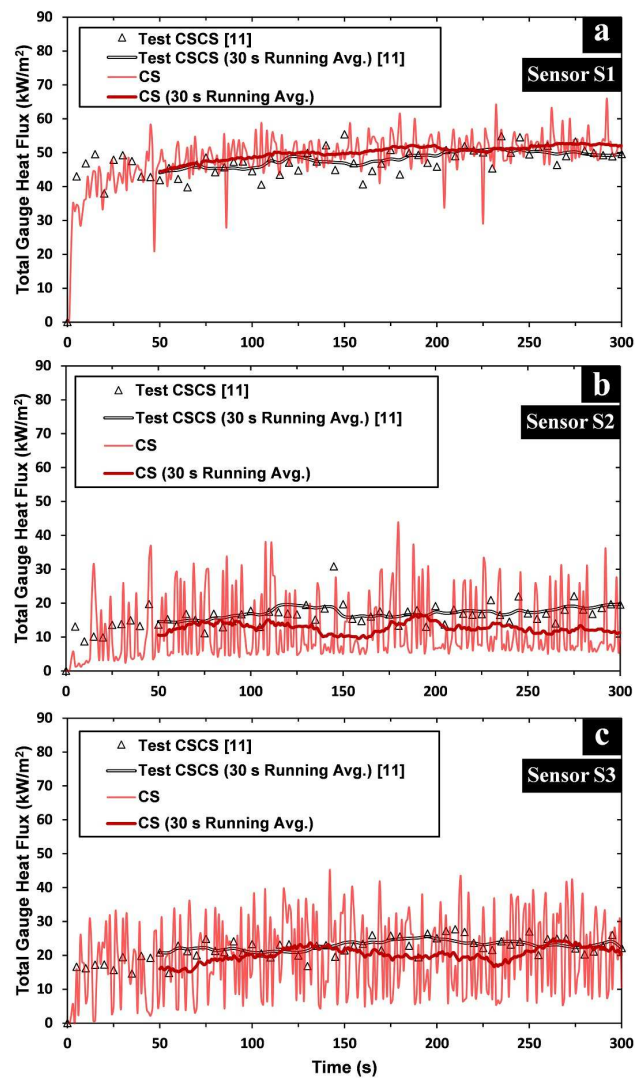

Figure 6: Total gauge heat fluxes at the locations of sensors S1 to S3 in simulation CS1 versus those in test CSCS [11]: see Fig. 1 for the locations of heat flux sensors. Thick solid lines correspond to $30 \mathrm{~s}$ running average profiles.

with the corresponding total gauge heat fluxes recorded in test CSCS [11]. The total gauge heat fluxes in simulation CS1 show large fluctuations, particularly at the location of sensors S2 and S3 (see Fig. 6.b and c). This is because sensors S2 and S3 are further away from the burner, whereas sensor S1 is located closest to the burner and is engulfed by the flames (Fig. 4). At all sensor locations, after $t=50 \mathrm{~s}$, the heat fluxes from the burner level off. The $30 \mathrm{~s}$ running average profiles at the location of sensor S1 reveal that deviations are as small as $4 \%$ on average. This confirms that the choice of a radiant fraction value of 0.3 , also implemented in [20], is reasonable for the propane burner. The running average profiles of sensors S2 and S3 show 
larger deviations from the corresponding experimental profiles (26\% and $13 \%$ on average, respectively). This suggests that it is challenging to precisely pre-

dict the instantaneous flame heights and widths, contributing to heat flux fluctuations at the location of sensor S3 and S2, respectively.

\subsection{MDF panel cases}

\subsubsection{Heat Release Rate (HRR) and mass loss rate (MLR)}

The predictions of HRR and MLR evolutions are shown in Fig. 7, along with experimental data [12]. During the first $50 \mathrm{~s}$, the predicted HRR evolution profiles follow the experimental average profile very closely. Further on, however, simulation ND1 predicts the fire growth behavior much more closely than simulation UD1. Most importantly, the magnitude and the timing of the peak HRR show considerable differences between ND1 and UD1. For ND1, the magnitude of the peak HRR $(159 \mathrm{~kW})$ is nearly within experimental uncertainty $(153 \pm 5 \mathrm{~kW})$, whereas UD1 shows an underestimation of $16 \%(129 \mathrm{~kW})$. Similarly, the timing of the peak HRR (156 s in the experiments) is overestimated by only $6 \%$ in simulation ND1 (165 s), versus $31 \%$ in UD1 $(204 \mathrm{~s})$. Between $t=200 \mathrm{~s}$ and $300 \mathrm{~s}$, the HRR profile of simulation ND1 drops and eventually reaches that of UD1. After $t=300 \mathrm{~s}$, however, the profiles diverge again as the HRR profile of simulation ND1 continues to drop rapidly. After $t=400 \mathrm{~s}$, simulation ND1 mostly underestimates the decay phase of the corner fire, by as much as $32 \mathrm{~kW}$ at $t=588 \mathrm{~s}$, whereas simulation UD1 reflects the decay phase very accurately. Overall, the HRR evolution predicted by ND1 can be considered more accurate during the fire growth period, while that of UD1 captures the later burning phase better. 

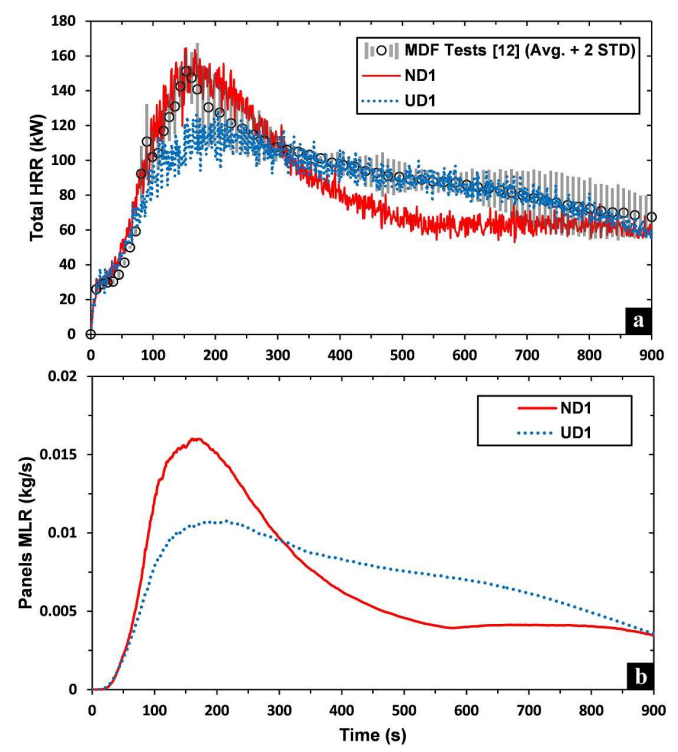

Figure 7: The temporal evolution of HRR in simulations ND1 and UD1 versus experiments [12] (top), and the evolution of MLR from the panels in simulations ND1 and UD1 (bottom): the presented HRR evolution for the MDF tests [12] is the average of three repeatability experiments (tests MM1, MM2 and MM3) with two standard deviations (shown as $\|$ ॥॥ ).

It is noteworthy that although the absolute value of peak HRR and its timing in the simulations are dependent on the values of various simulation parameters (e.g., see [29] for sensitivity to different wall function choices), the relative differences between simulations ND1 and UD1 still persist, as they are caused by the highly different panel density profiles in these simulations. This can be understood more clearly from Fig. 7.b. According to Fig. 7.b, the peak MLR from the panels in simulation ND1 is over $50 \%$ higher than that in simulation UD1. This is essentially because the surface density of MDF panels is higher in simulation ND1. Correspondingly, it is expected that when the density near the surface and midway through the thickness of 
the MDF panels is modeled more accurately, there is more potential for the simulations to capture the high peak MLR at the initiation of pyrolysis of MDF material, just as observed in the modeling of the FPA tests [17].

\subsubsection{Total heat fluxes}

We evaluate the total heat fluxes in the simulations by estimating the total gauge heat fluxes according to Eq. (14). As shown in Fig. 8, simulation UD1 features higher heat fluxes than ND1 in general, except during the period between $t=100 \mathrm{~s}$ and $t=300 \mathrm{~s}$, particularly at the location of sensors S2 and S3 (Fig. 8.b and c). The latter is essentially due to the HRR being $26 \%$ higher in simulation ND1 during this period on average (note Fig. 7.a between $t=100 \mathrm{~s}$ and $t=300 \mathrm{~s}$ ). After $t=300 \mathrm{~s}$, the HRR in simulation UD1 becomes higher than that of ND1 and the heat fluxes are predominantly higher as well.

The heat flux predictions in both simulations ND1 and UD1 can be considered most reasonable near the burner, i.e., at the location of sensor S1 (Fig. 8.a). Most of what is measured at this location is due to the direct thermal attack from the burner: about $52 \mathrm{~kW} / \mathrm{m}^{2}$, or $85 \%$ of the total heat flux, is the steady heat flux from the burner (compare Fig. 6.a for simulation CS1 with Fig. 8.a for simulations ND1 and UD1). At locations further away from the burner, the accurate prediction of fire presence proves challenging for both simulations ND1 and UD1, resulting in large fluctuations in the heat flux predictions at these locations, just as observable in simulation CS1 with inert panels (note Fig. 6.b and 6.c). 

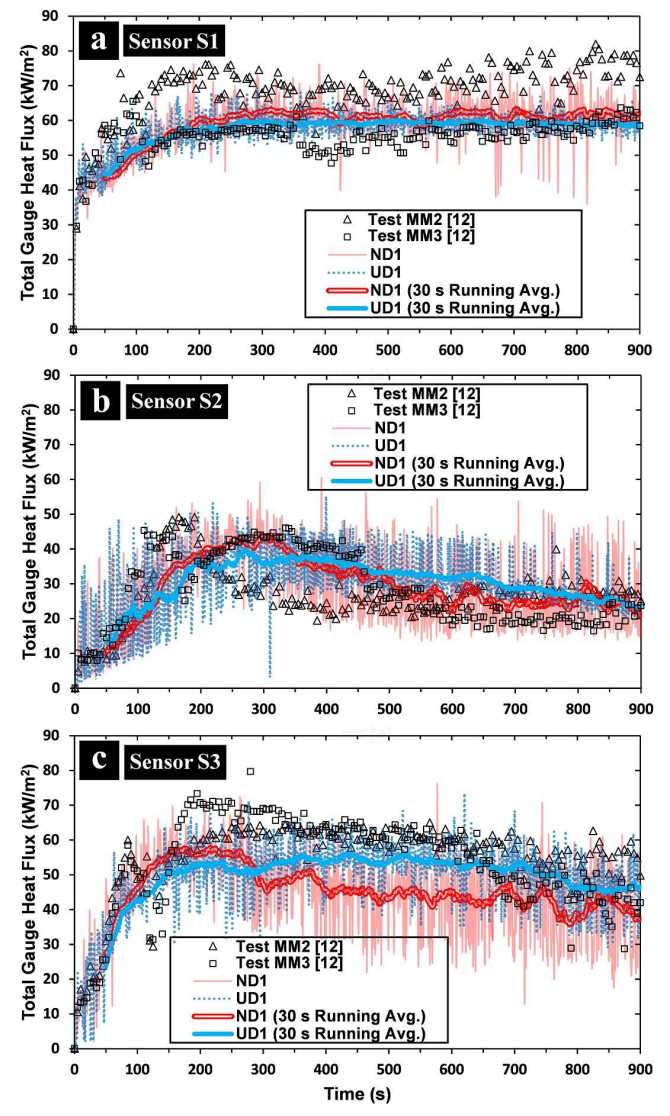

Figure 8: Total gauge heat fluxes at the locations of sensors S1 to S3 in simulations ND1 and UD1 versus those in the MDF experiments [12]: see Fig. 1 for the locations of heat flux sensors. Thick lines correspond to $30 \mathrm{~s}$ running average profiles.

\subsubsection{Flame heights}

The instantaneous flame heights in simulations ND1 and UD1 are determined using the integrated HRR, as explained in section 4.1.1. The results are shown in Fig. 9, along with corresponding data from the experiments [12].

The flame heights in simulations ND1 and UD1 show minimal differences from one another, although UD1 features generally slightly higher flame heights, occasionally by as large as $0.3 \mathrm{~m}$.

Both simulations ND1 and UD1 generally tend to overestimate the flame heights observed in the MDF experiments [12] (see Fig. 9). The deviation is $23 \%$ on average, with respect to the mean of the MDF tests [12]. 


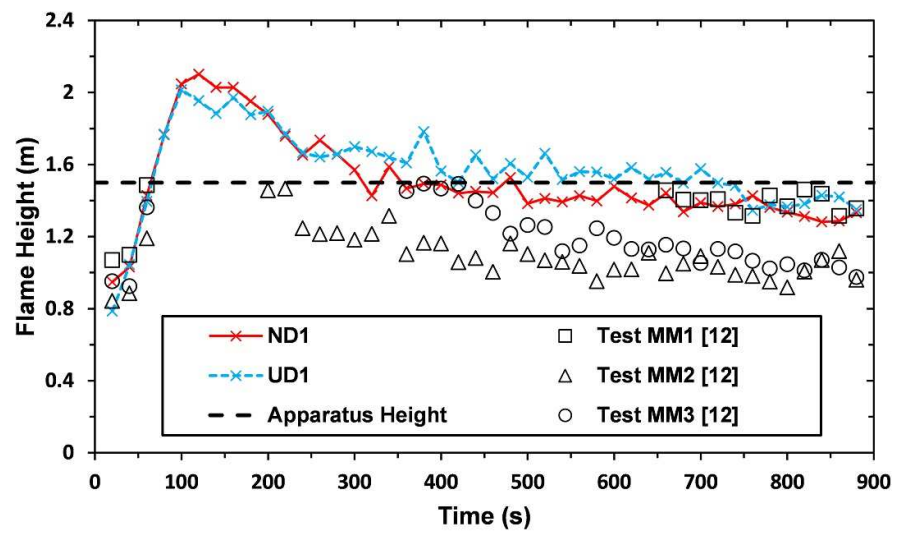

Figure 9: Averaged flame heights in simulations ND1 and UD1 versus those in the MDF tests [12]: the averaging of the flame heights in the simulations is performed over a period of $2 \mathrm{~s}$, as in [12], with a time resolution of $0.01 \mathrm{~s}$. Flame heights higher than the apparatus height $(1.5 \mathrm{~m})$ are not reported in the experiments [12].

\subsubsection{Fire spread and pyrolysis front propagation}

The overall fire spread in MDF simulations ND1 and UD1 are shown through Fig. 10 and 11, along with corresponding footage snapshots from test MM3 [12], as the footage in this test is available from both the long and short panel view angles. The flames are already present near the top of the panels at $t=60 \mathrm{~s}$ in the simulations, but this happens nearly $40 \mathrm{~s}$ later in test MM3. This is in line with both simulations slightly overestimating the HRRs at this time (see Fig. 7.a), causing the flames to spread faster as well, both upward and laterally.

In order to carefully quantify the differences between simulations ND1 and UD1, the propagation of the pyrolysis front is monitored on the surface of the MDF panels. The location of the pyrolysis front on the surface can be associated with various parameters, such as temperature [47], or pyrolysis mass flux [48]. Instead of assuming a fixed pyrolysis temperature or mass flux, we propose a new diagnostic to determine the position of the front, namely 

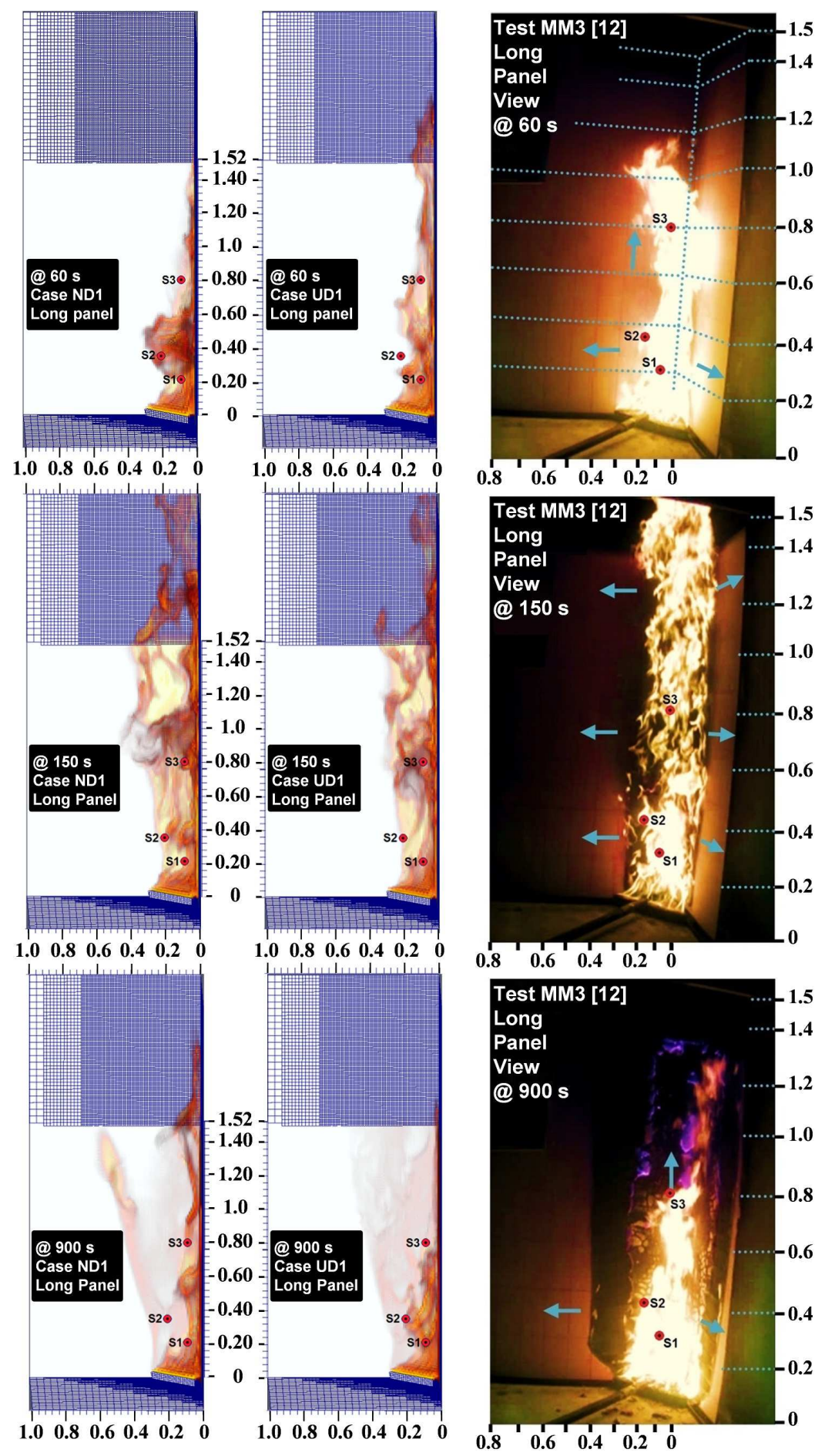

Figure 10: Long panel view of flame spread in simulations ND1 and UD1 versus corresponding experimental footage snapshots [12] (distance units in meters): volumetric HRR $\left(\mathrm{kW} / \mathrm{m}^{3}\right)$ is considered for visualization of the flames in the simulations, as in [46]. For locations of sensors S1 to S3 (), see Fig. 1. 

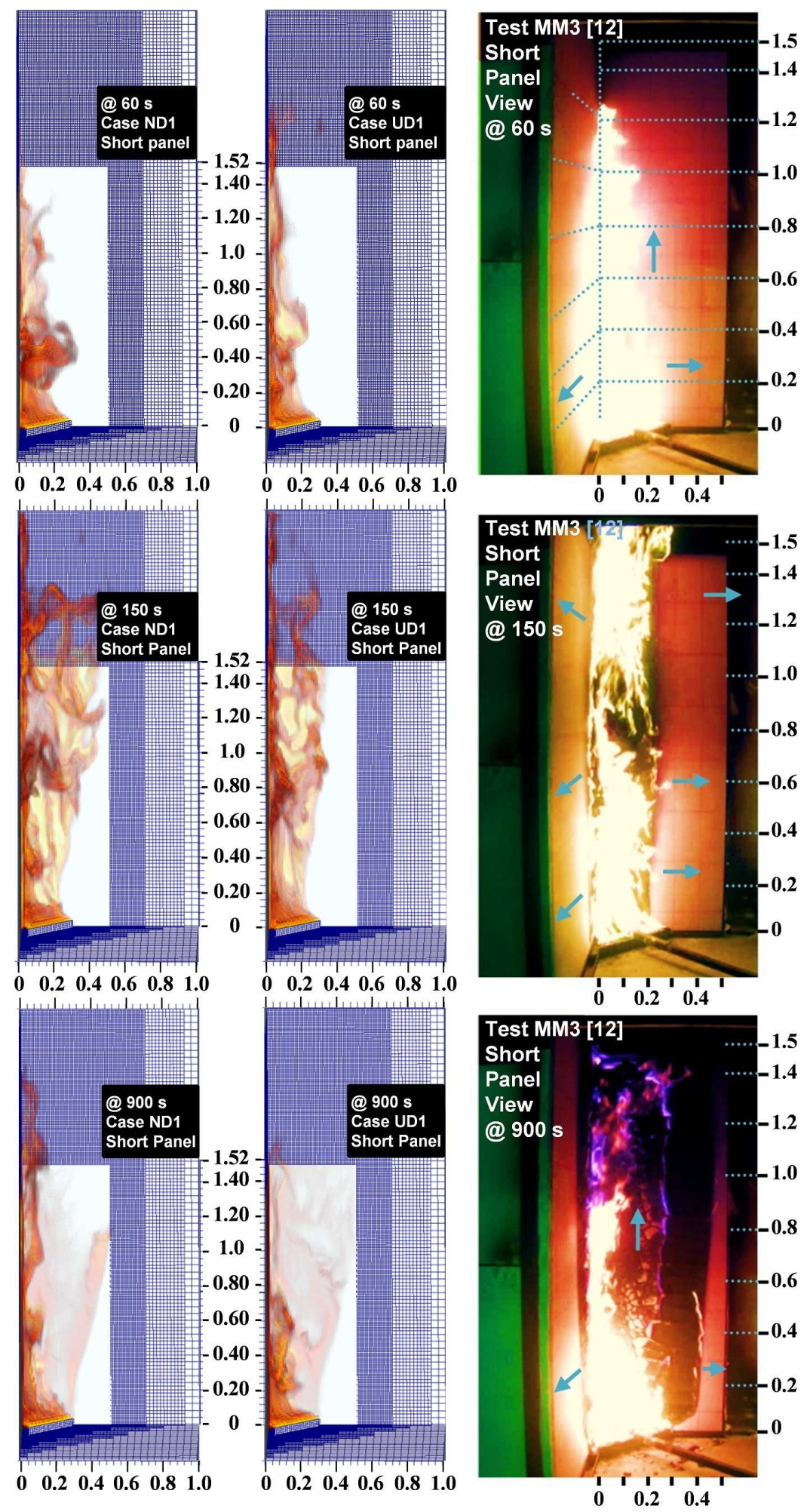

Figure 11: Short panel view of flame spread in simulations ND1 and UD1 versus corresponding experimental footage snapshots [12] (distance units in meters): volumetric HRR $\left(\mathrm{kW} / \mathrm{m}^{3}\right)$ is considered for visualization of the flames in the simulations, as in [46]. 


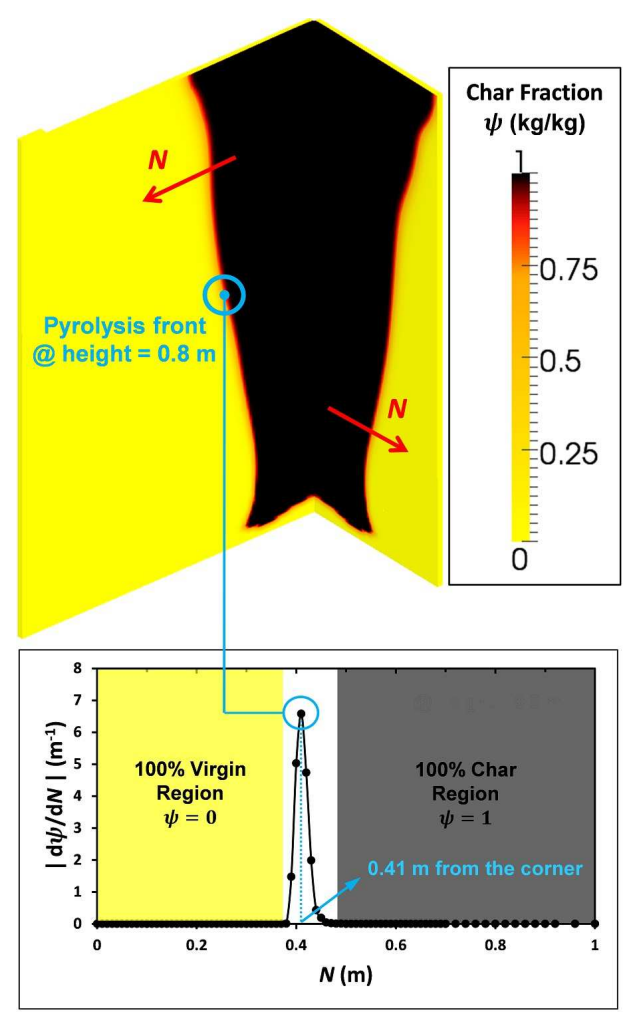

Figure 12: Pyrolysis front on the long panel at height $0.8 \mathrm{~m}$ shown visually (top) and diagnostic determination of its location using Eq. (15) via the position of highest char fraction gradient along the spread direction (bottom).

the location of highest char fraction gradient along the spread direction, i.e., where:

$$
\left|\frac{d \psi}{d N}\right|=\text { maximum }
$$

in which $\psi$ denotes the char fraction by mass and $N$ is the Cartesian coordinate along the spread direction. Essentially, Eq. (15) translates to the location of highest char fraction gradient in the narrow region between the completely virgin and completely charred material. This is illustrated in Fig. 12.

The propagation of the pyrolysis fronts on the panels in MDF simulations ND1 and UD1 is illustrated in Fig. 13 and 14, along with corresponding data from test MM3 [12]. 
Figure 13 reveals that the pyrolysis front in simulation ND1 spreads faster than that in simulation UD1 during the period where the HRR is higher (Fig. 7.a, $t<300 \mathrm{~s}$ ). Afterwards, the UD results catch up. This confirms the importance of the non-uniform mass density in the simulations: the higher MLR (Fig. 7.b) leads to larger flame regions and thus stronger heat feedback. This positive feedback loop leads to faster spread of the pyrolysis front. As the top has already been reached, this spread is essentially lateral. Once the MLR becomes higher for UD, the pyrolysis front moves faster in this simulation than in ND. Given this influential role of MLR, it is expected that when the density distribution through the thickness of the MDF panels is modeled more accurately, there is more potential for the simulations to capture the correct pyrolysis and flame spread on the surface of MDF material.

In the lower regions near the burner, the spread of the pyrolysis front in both simulations UD1 and ND1 is much less extensive than that in test MM3 [12], with deviations as large as $0.15 \mathrm{~m}$ (see Fig. 13 at $Y=0.2 \mathrm{~m}$ ). This is essentially because the prediction of fire presence and the heat fluxes near the burner proves challenging in the simulations (refer to explanations for Fig. 6.b and c). As the positions of the fronts in regions near the burner follow each other closely in simulations UD1 and ND1, the panel density distribution can be considered to not play a significant role in the propagation of the pyrolysis front in this region.

At nearly midway along the height of the panels, where $0.6 \mathrm{~m}<Y<0.8$ $\mathrm{m}$, the propagation of the lateral pyrolysis front in the simulations follows that of test MM3 [12] most closely. This is expected because the shape of the flame envelope is predicted more accurately in this region (see Fig. 10 and 

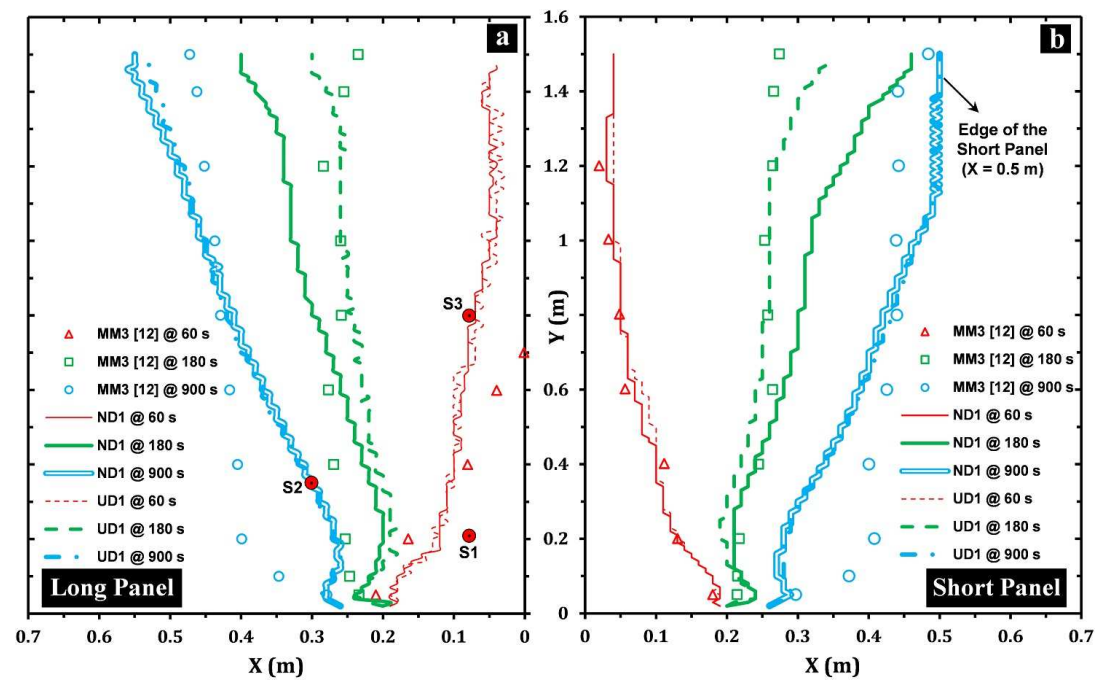

Figure 13: Pyrolysis front propagation over the surface of the panels in simulations ND1 and UD1 versus that in test MM3 [12] on (a) the long panel and (b) the short panel: $X$ and $Y$ denote the horizontal and vertical distance of the spread front from the corner, respectively. For exact locations of sensors S1 to S3 ( see Fig. 1.

11). The non-uniform panel density distribution does play a visible role in the propagation of the pyrolysis front in this region: simulation ND1 features faster front spread than UD1, with deviations up to $0.05 \mathrm{~m}$ (Fig. 13 at $Y=$ $0.8 \mathrm{~m})$.

In the upper regions near the top of the panels, the spread extent of pyrolysis front is overestimated in the simulations, with deviations up to $0.17 \mathrm{~m}$ from that in test MM3 [12] (Fig. 13 at $Y=1.5 \mathrm{~m}$ ). It is expected that lateral pyrolysis spread at higher heights and further away from the burner is governed more by surface properties of the panels. Note that this region is where the non-uniform panel density distribution plays the most significant role in the propagation of the pyrolysis front: simulation ND1 features considerably faster front spread than UD1, with deviations up to $0.12 \mathrm{~m}$ (Fig. 13.b at $Y=1.5 \mathrm{~m}$ ).

It is evident from Fig. 13 that the spread patterns on the long and short 


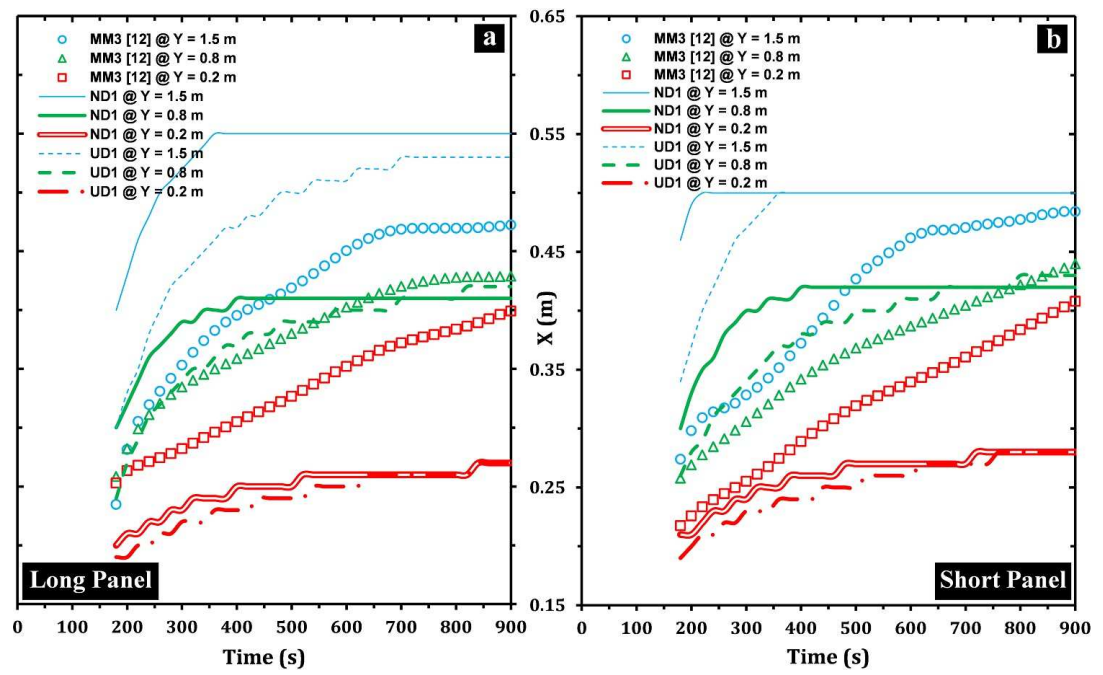

Figure 14: Time history of lateral pyrolysis front propagation over the surface of the panels in simulations ND1 and UD1 versus that in test MM3 [12] on (a) the long panel and (b) the short panel: as discussed in [12], the time history of lateral front propagation is tracked for $t>180 \mathrm{~s}$, so that the front is beyond the region above the burner. $X$ and $Y$ denote the horizontal and vertical distance of the spread front from the corner, respectively.

panels are more or less symmetric in the simulations, while in test MM3 the spread on the long panel is slower than that on the short panel. As discussed in $[11,49]$, the thermal attack in the configuration of SBI is observed to be slightly stronger on the short panel due to a set-up specific phenomenon related to the supply of air from the bottom of the testing trolley, leading to higher heat fluxes and thus higher panel temperatures on the short panel side. In our simulations, however, the computational domain does not include the entire testing enclosure (only the testing trolley itself has been considered), leading to a more or less symmetric air supply and flame spread on the panels. It has been illustrated in [50] that a larger computational domain including the entire enclosure has the potential to reasonably capture these asymmetry effects caused by the specific geometry of SBI, but this is beyond the scope of the present study. 
Both MDF simulations ND1 and UD1 feature faster spread on the panels when compared to test MM3 [12] (note Fig. 13). This is true even for the fast burning short panel in test MM3. At $t=60 \mathrm{~s}$, the spread of the front along the upper edge of the short panel in both simulations ND1 and MD1 is $0.04 \mathrm{~m}$ versus $0.02 \mathrm{~m}$ in test MM3. That is, the average spread rate in the simulations is twice as fast as that in test MM3 over the first $60 \mathrm{~s}$. This difference grows even larger toward $t=180 \mathrm{~s}$, with values of $0.46 \mathrm{~m}$ and 0.34 $\mathrm{m}$ in simulations ND1 and UD1 versus $0.11 \mathrm{~m}$ in test MM3, respectively. At $t=900 \mathrm{~s}$, the final spread along the upper edge of the short panel is all the way to $0.5 \mathrm{~m}$ in both ND1 and UD1, versus $0.48 \mathrm{~m}$ in test MM3. Noting the temporal profiles of spread in Fig. 14, similar behavior is observed. Most notably, the initial spread in both simulations ND1 and UD1 is faster than that in test MM3, although the profiles level off quicker too, occasionally showing more than 300 s difference in level-off time.

\section{Conclusions}

The influence of non-uniform mass density distribution in numerical simulations of fire spread over MDF panels in a corner set-up has been investigated using FireFOAM 2.2.x $[13,14]$. This is accomplished through simulations of

several SBI corner fire experiments $[11,12]$ conducted with MDF panels and a test with inert Calcium Silicate (CS) panels, using model-effective material properties determined from bench-scale pyrolysis tests conducted in an FPA [17]. The convection and radiation from the gas phase are modeled by means of empirical expressions with adjusted parameters. Both uniform and nonuniform through-thickness density distributions have been considered for the 
MDF material, where the non-uniform density profile of MDF was obtained from the FPA tests [17].

Firstly, an assessment has been made of the predicted flame height and heat fluxes of the burner itself through a simulation case corresponding to a test with inert CS panels [11], involving no flame spread. Consequently, the flame height estimation is found to be satisfactory for the burner itself (with absolute average deviations of $5 \%$ from the experimental value [11]). Similarly, the total gauge heat fluxes from the burner are predicted reasonably near the burner (with average deviation of $4 \%$ from the experimental value [11]). Most deviations are observable further away from the corner, where an accurate prediction of the presence of flames proves challenging, resulting in large fluctuations in the heat flux predictions.

The magnitude and the timing of the peak HRR observed for the MDF panels are found to be significantly influenced by the non-uniform definition of the through-thickness density profile, with the predicted value for peak HRR being $20 \%$ higher in the non-uniform density simulation when compared with the uniform density simulation. This has been explained through the higher peak mass loss rate at the initiation of pyrolysis of MDF material, also observed in the FPA tests [17].

The flame spread is found to be significantly influenced by the nearsurface density definition, namely higher surface densities are associated with higher pyrolysis propagation rates over the surface. This is particularly the case in regions further away from the corner, where the accurate prediction of fire presence proves challenging for both cases with uniform and non-uniform through-thickness density profiles, with large fluctuations in the total heat 
flux predictions.

A new diagnostic has been proposed to determine the pyrolysis front location and spread on the surface of the panels, based on the location of highest char fraction gradient along the spread direction, i.e., Eq. (15). This is more systematic and less arbitrary compared to criteria assuming a fixed temperature or mass flux for the pyrolysis boundary. The proposed diagnostic relies solely on already computed char fraction values. Thus, it is expected to be very helpful for studies of pyrolysis propagation on the surface of charring materials.

It is recommended for similar future computational assessments involving flame spread scenarios over MDF panels to consider quantifying the nonuniform panel density effects, as this study shows large implications from the non-uniform mass density on the evolution of key parameters such as HRR, lateral flame spread and char formation. For more elaborate analyses, it is advisable to consider modeling water evaporation and movement inside the wood product [51], explore more sophisticated radiation modeling approaches [52], and evaluate gas phase velocities and temperatures in CFD simulations against experimental data.

\section{Acknowledgments}

This research has been funded by the Research Foundation Flanders (FWO-Vlaanderen, Belgium) under project number G004912N, and by FM Global with the strategic research program on fire modeling. The authors gratefully acknowledge the support of WFRGent NV for their eminent support with materials and equipment. 


\section{Nomenclature Listing}

\begin{tabular}{|c|c|c|c|}
\hline$a$ & absorptivity & $\theta$ & computational cell width on the fire source $(\mathrm{m})$ \\
\hline A & pre-exponential factor $\left(\mathrm{s}^{-1}\right)$ & $\lambda$ & thermal conductivity $\left(\mathrm{W} \cdot \mathrm{m}^{-1} \cdot \mathrm{K}^{-1}\right)$ \\
\hline$c_{I}$ & dynamic Smagorinsky model parameter & $\mu$ & dynamic viscosity $\left(\mathrm{kg} \cdot \mathrm{m}^{-1} \cdot \mathrm{s}^{-1}\right)$ \\
\hline$c_{s}$ & Smagorinsky model parameter & $\xi$ & ratio between max and min of local density in MDF panels \\
\hline$c_{p}$ & specific heat capacity $\left(\mathrm{J} \cdot \mathrm{kg}^{-1} \cdot \mathrm{K}^{-1}\right)$ & $\rho$ & panel density $\left(\mathrm{kg} \cdot \mathrm{m}^{-3}\right)$ \\
\hline$D^{*}$ & characteristic fire diameter $(\mathrm{m})$ & $\bar{\rho}_{\text {gas }}$ & Reynolds averaged mean gas density $\left(\mathrm{kg} \cdot \mathrm{m}^{-3}\right)$ \\
\hline$E_{a}$ & activation energy $\left(\mathrm{J} . \mathrm{mol}^{-1}\right)$ & $\rho_{\text {gas }}$ & gas density $\left(\mathrm{kg} \cdot \mathrm{m}^{-3}\right)$ \\
\hline$g$ & gravitational acceleration $\left(\mathrm{m} . \mathrm{s}^{-2}\right)$ & $\sigma$ & Stefan-Boltzmann constant $\left(5.67 \times 10^{-8} \mathrm{~W} \cdot \mathrm{m}^{-2} \cdot \mathrm{K}^{-4}\right)$ \\
\hline$h$ & conv. heat transfer coeff. $\left(\mathrm{W} \cdot \mathrm{m}^{-2} \cdot \mathrm{K}^{-1}\right)$ & $\tau$ & time scale $(\mathrm{s})$ \\
\hline$h_{m}$ & mass transfer coefficient $\left(\mathrm{kg} \cdot \mathrm{m}^{-2} \cdot \mathrm{s}^{-1}\right)$ & $\chi_{\text {rad }}$ & radiant fraction of chemical HRR \\
\hline$H_{f}$ & mean flame height (m) & $\psi$ & char fraction by mass \\
\hline$H_{p y r}$ & heat of pyrolysis $\left(\mathrm{J}_{\mathrm{kg}}{ }^{-1}\right)$ & $\overline{\dot{\omega}_{F}^{\prime \prime \prime}}$ & Reynolds averaged fuel mass reaction rate $\left(\mathrm{kg} \cdot \mathrm{m}^{-3} \cdot \mathrm{s}^{-1}\right)$ \\
\hline$k$ & turbulent kinetic energy & & \\
\hline$L$ & panel thickness & \multicolumn{2}{|c|}{ Subscripts } \\
\hline$m$ & mass of MDF material (kg) & $\infty$ & ambient air \\
\hline$\dot{m}^{\prime \prime}$ & gaseous mass flux $\left(\mathrm{kg} \cdot \mathrm{m}^{-2} \cdot \mathrm{s}^{-1}\right)$ & bulk & bulk property \\
\hline$n$ & reaction order & $c$ & char MDF \\
\hline$N$ & Cartesian coordinate of spread direction & $\operatorname{conv}$ & convective \\
\hline$\dot{q}^{\prime \prime}$ & heat flux $\left(\mathrm{W} . \mathrm{m}^{-2}\right)$ & $E D M$ & eddy dissipation combustion \\
\hline$\overline{\dot{q}_{c o m b}^{\prime \prime \prime}}$ & volumetric $\operatorname{HRR}\left(\mathrm{W} / \mathrm{m}^{3}\right)$ & eff & effective \\
\hline$\dot{Q}$ & heat release rate $\left(10^{3} . \mathrm{W}\right)$ & $F$ & propane fuel \\
\hline$r$ & stoichiometric ratio of fuel $/ \mathrm{O}_{2}$ by mass & flam & flaming convection upper limit \\
\hline$T$ & temperature $(\mathrm{K})$ & gas & ambient and combustion gases \\
\hline$\widetilde{T}$ & Favre-filtered gas temperature $(\mathrm{K})$ & gauge & gauge heat flux meter (water cooled) \\
\hline$t$ & time $(s)$ & $i n c$ & net incident \\
\hline$X$ & horizontal distance from corner (m) & lam & laminar convection at low pyrolyzate flow \\
\hline$Y$ & vertical distance from corner $(\mathrm{m})$ & $\operatorname{mix}$ & mixing for reaction in the gas phase \\
\hline$\widetilde{Y}$ & Favre-filtered gaseous species mass fraction & $\mathrm{O}_{2}$ & oxygen \\
\hline \multirow[t]{2}{*}{$Z$} & depth from panel surface $(\mathrm{m})$ & $p$ & constant pressure \\
\hline & & panel & MDF panel \\
\hline Greek & letters & pyr & pyrolysis \\
\hline$\alpha$ & molecular thermal diffusivity $\left(\mathrm{m}^{2} . \mathrm{s}^{-1}\right)$ & pyrol & pyrolyzate \\
\hline$\Delta$ & LES filter size $(\mathrm{m})$ & rad & radiative \\
\hline$\Delta H$ & heat of combustion $\left(\mathrm{J} \mathrm{kg}^{-1}\right)$ & sgs & sub-grid scale \\
\hline$\Delta x$ & effective grid spacing in direction $\mathrm{x}(\mathrm{m})$ & thresh & threshold for flaming convection \\
\hline$\Delta y$ & effective grid spacing in direction $\mathrm{y}(\mathrm{m})$ & tot & total \\
\hline$\Delta z$ & effective grid spacing in direction $\mathrm{z}(\mathrm{m})$ & $v$ & virgin $\mathrm{MDF}$ \\
\hline$\varepsilon$ & emissivity & $V$ & gaseous volume \\
\hline
\end{tabular}




\section{References}

[1] Z. Cai, H.J. Muehl, J.E. Winandy, Effects of pressing schedule on formation of vertical density profile for MDF panels, 40th International Wood Composites Symposium, Seattle, Washington, April 11-12 2006.

[2] X. Wang, M. Mohammad, L.J. Hu, A. Salenikovich, Evaluation of density distribution in wood-based panels using X-ray scanning, Proceedings of the 14th International Symposium on Nondestructive Testing of Wood, University of Applied Sciences Eberswalde, Germany, 2005.

[3] X. Huang, K. Li, H. Zhang, Modelling bench-scale fire on engineered wood: Effects of transient flame and physicochemical properties, Proc. Combust. Inst. 36 (2): 3167-3175, 2017.

[4] K.Y. Li, X. Cheng, H. Zhang, A simplified model on vertical density profile and shrinkage ratio of virgin and charred medium density fibreboard, Fire Mater. 38 (2014): 659-672.

[5] K.Y. Li, C.M.Fleischmann, M.J. Spearpoint, Determining thermal physical properties of pyrolyzing New Zealand medium density fibreboard (MDF), Chem. Eng. Sci. 95 (2013): 211-220.

[6] EN 13823, Reaction to fire tests for building products (2002) building products excluding floorings exposed to the thermal attack by a single burning item, European Standard, 2002.

[7] ISO 12136, Reaction to fire tests measurement of material properties using a fire propagation apparatus, International Standards Organization (ISO), Geneva, Switzerland, 2011. 
[8] ASTM E2058-13a, Standard test methods for measurement of material flammability using a Fire Propagation Apparatus (FPA), ASTM International, West Conshohocken, Pennsylvania, US, 2013.

[9] ISO 9705, ISO room corner (1993) international standard - fire tests full-scale room test for surface products, International Standards Organization (ISO), 1993.

[10] R. van Mierlo, B. Sette, The Single Burning Item (SBI) test method a decade of development and plans for the near future, HERON 50 (2005): 191-207.

[11] D. Zeinali, S. Verstockt, T. Beji, G. Maragkos, J. Degroote, B. Merci, Experimental study of corner fires-Part I: Inert panel tests, Combust. Flame 189 (2018): 472490.

[12] D. Zeinali, S. Verstockt, T. Beji, G. Maragkos, J. Degroote, B. Merci, Experimental study of corner fires-Part II: Flame spread over MDF panels, Combust. Flame 189 (2018): 491505.

[13] Y. Wang, P. Chatterjee, J.L. de Ris, Large eddy simulation of fire plumes, Proc. Combust. Inst. 33 (2011): 2473-2480.

[14] FireFOAM version 2.2.x, Available at https://github.com/fireFoam$\mathrm{dev} /$ fireFoam-2.2.x.

[15] OpenFOAM CFD package, Available at http://www.openfoam.com.

[16] D. Drysdale, Combustion and energy release, in: An introduction to fire dynamics, John Wiley and Sons, Chichester (2011), p. 21. 
[17] G. Agarwal, M. Chaos, Y. Wang, D. Zeinali, B. Merci, Pyrolysis model properties of engineered wood products and validation using transient heating scenarios, 14th International Conference and Exhibition on Fire Science and Engineering, Royal Holloway College, Nr Windsor, UK, 4-6 July 2016: Interscience Communications.

[18] M. Chaos, M.M. Khan, N. Krishnamoorthy, J.L. de Ris, S.B. Dorofeev, Evaluation of optimization schemes and determination of solid fuel properties for CFD fire models using bench-scale pyrolysis tests, Proc. Combust. Inst. 33 (2011): 2599-2606.

[19] M. Hjohlman, P. Andersson, P. van Hees, Flame spread modelling of complex textile materials, Fire Technol. 47 (2011): 85-106.

[20] K. McGrattan, S. Hostikka, R. McDermott, J. Floyd, C.Weinschenk, K.Overholt, Fire dynamics simulator user's guide (sixth edition), FDS version 6.5.1, National Institute of Standards and Technology (NIST), 2016, pp. 288.

[21] M. Chaos, Spectral aspects of bench-scale flammability testing: application to hardwood pyrolysis, Fire Saf. Sci. 11 (2014): 165-178.

[22] C. Di Blasi, Modeling and simulation of combustion processes of charring and non-charring solid fuels, Prog. Energy Combust. Sci. 19 (1993): 71104.

[23] T. Poinsot, D. Veynante, Theoretical and numerical combustion, Second ed., Edwards, 2012. 
[24] Y. Ding, C. Wang, S. Lu, Modeling the pyrolysis of wet wood using FireFOAM, Energy Convers. Manage. 98 (2015): 500-506.

[25] D. Zeinali, G. Agarwal, A. Gupta, G. Maragkos, N. Ren, M. Chaos, Y. Wang, T. Beji, J. Degroote, B. Merci, Computational analysis of pyrolysis and flame spread for MDF panels placed in a corner configuration, the 8th International Seminar on Fire and Explosion Hazards, University of Science and Technology of China, Hefei, China, 2016.

[26] I.S. Ertesvåg, B.F. Magnussen, The eddy dissipation turbulence energy cascade model, Combust. Sci. Technol. 159 (2000): 213-235.

[27] G. Maragkos, T. Beji, B. Merci, Implementation and evaluation of the dynamic Smagorinsky model and an eddy dissipation model with multiple reaction time scales in FireFOAM, 10th Mediterranean Combustion Symposium, Naples, Italy, 17-21 September 2017.

[28] P. Moin, K. Squires, W. Cabot, S. Lee, A Dynamic Subgridscale Model for Compressible Turbulence and Scalar Transport, Phys. Fluids A 3 (1991): 2746-2757.

[29] T.E. Skydt, CFD modelling of flame spread in corner fires, Master's thesis, Departments of Civil Engineering (Technical University of Denmark) and Flow, Heat and Combustion Mechanics (Ghent University), Kongens Lyngby, Denmark, 2017.

[30] D.B. Spalding, A Single Formula for the Law of the Wall, Journal of Applied Mechanics 28 (1961):455-458. 
[31] W. Sutherland, LII. The viscosity of gases and molecular force, Philosophical Magazine Series 536 (1893): 507-531.

[32] R.C. Reid, J.M. Prausnitz, T.K. Sherwood, The properties of gases and liquids, McGraw-Hill, 1977.

[33] A. Burcat, Thermochemical data for combustion calculations, in: W.C. Gardiner (Ed.), Combustion Chemistry, Springer US, New York, NY, 1984, pp. 455-473.

[34] P. Chatterjee, Y. Wang, K.V. Meredith, S.B. Dorofeev, Application of a subgrid soot-radiation model in the numerical simulation of a heptane pool fire, Proc. Combust. Inst. 35 (2015): 2573-2580.

[35] M.M. Khan, A. Tewarson, M. Chaos, Combustion characteristics of materials and generation of fire products, in: M.J. Hurley, D.T. Gottuk, J.R. Hall Jr., K. Harada, E.D. Kuligowski, M. Puchovsky, J.L. Torero, J.M. Watts Jr., C.J. Wieczorek (Eds.), SFPE Handbook of Fire Protection Engineering, NY: Springer, New York, 2016, pp. 1143-1232.

[36] A. Hamins, K. Konishi, P. Borthwick, T. Kashiwagi, Global properties of gaseous pool fires, Symposium (International) on Combustion 26 (1996): 1429-1436.

[37] N. Ren, Y. Wang, S., Vilfayeau, A., Trouvé, Large eddy simulation of turbulent vertical wall fires supplied with gaseous fuel through porous burners, Combust. Flame, 169 (2016):194-208.

[38] J.G. Quintiere, Fundamentals of fire phenomena, John Wiley and Sons, Chichester, United Kingdom, 2006. 
[39] Y. Wang, K. Meredith, X. Zhou, P. Chatterjee, Y. Xin, M. Chaos, N. Ren, S. Dorofeev, Numerical simulation of sprinkler suppression of rack storage fires, Fire Saf. Sci. 11 (2014): 1170-1183.

[40] P.L. Blackshear, K.A. Murty, Heat and mass transfer to, from, and within cellulosic solids burning in air, Symposium (International) on Combustion 10 (1965): 911-923.

[41] D. Gisen, Generation of a 3D mesh using snappyHexMesh featuring anisotropic refinement and near-wall layers, 11th International Conference on Hydroscience \& Engineering, Hamburg, Germany, 2014: Bundesanstalt für Wasserbau, pp. 983-990.

[42] OpenFOAM user guide, Chapter 5, OpenCFD Ltd, 2016.

[43] G. Heskestad, Fire plumes, flame height, and air entrainment, in: M.J. Hurley, D. Gottuk, J.R. Hall, K. Harada, E. Kuligowski, M. Puchovsky, J. Torero, J.M. Watts, C. Wieczorek (Eds.), SFPE Handbook of Fire Protection Engineering, Springer New York, New York, NY, 2016, pp. $396-428$.

[44] T.G. Ma, J.G. Quintiere, Numerical simulation of axi-symmetric fire plumes: accuracy and limitations, Fire Saf. J. 38 (2003): 467-492.

[45] U. Wickström, Temperature calculation in fire safety engineering, Springer International Publishing, 2016.

[46] G.P. Forney, Smokeview, a tool for visualizing fire dynamics simulation data volume I: users guide (sixth edition), Smokeview version 6.3.9, National Institute of Standards and Technology (NIST), 2016. 
[47] S.R. Wasan, P. Rauwoens, J. Vierendeels, B. Merci, An enthalpy-based pyrolysis model for charring and non-charring materials in case of fire, Combust. Flame 157 (2010): 715-734.

[48] C. di Blasi, Processes of flames spreading over the surface of charring fuels: Effects of the solid thickness, Combust. Flame 97 (1994): 225-239.

[49] J. Zhang, M. Delichatsios, M. Colobert, Assessment of fire dynamics simulator for heat flux and flame heights predictions from fires in SBI tests, Fire Technol. 46 (2010): 291-306.

[50] G. Zhao, Numerical study on under-ventilated enclosure fires and flame spread on building faades, Doctoral thesis, Department of Flow, Heat and Combustion Mechanics, Ghent University, Ghent, 2017.

[51] Y. Ding, C. Wang, S. Lu, Modeling the pyrolysis of wet wood using FireFOAM, Energy Conversion and Management 98 (2015) 500-506.

[52] P. Chatterjee, J.L. de Ris, Y. Wang, S.B. Dorofeev, Application of a subgrid soot-radiation model in the numerical simulation of a heptane pool fire, Proceedings of the Combustion Institute 33 (2011) 2665-2671. 